\title{
From wood chips to pellets to milled pellets: The mechanical processing pathway of Austrian pine and European beech
}

Masche, Marvin; Puig-Arnavat, Maria; Jensen, Peter A.; Holm, Jens Kai; Clausen, Sønnik; Ahrenfeldt, Jesper; Henriksen, Ülrik B.

Published in:

Powder Technology

Link to article, DOI:

10.1016/j.powtec.2019.03.002

Publication date:

2019

Document Version

Peer reviewed version

Link back to DTU Orbit

Citation (APA):

Masche, M., Puig-Arnavat, M., Jensen, P. A., Holm, J. K., Clausen, S., Ahrenfeldt, J., \& Henriksen, U. B. (2019). From wood chips to pellets to milled pellets: The mechanical processing pathway of Austrian pine and European beech. Powder Technology, 350, 134-145. https://doi.org/10.1016/j.powtec.2019.03.002

\section{General rights}

Copyright and moral rights for the publications made accessible in the public portal are retained by the authors and/or other copyright owners and it is a condition of accessing publications that users recognise and abide by the legal requirements associated with these rights.

- Users may download and print one copy of any publication from the public portal for the purpose of private study or research.

- You may not further distribute the material or use it for any profit-making activity or commercial gain

- You may freely distribute the URL identifying the publication in the public portal 


\title{
From wood chips to pellets to milled pellets: the mechanical
}

\section{processing pathway of Austrian pine and European beech}

Marvin Masche ${ }^{a *}$, Maria Puig-Arnavat ${ }^{a}$, Peter A. Jensen ${ }^{a}$, Jens Kai Holm ${ }^{b}$, Sønnik Clausen ${ }^{a}$, Jesper Ahrenfeldt ${ }^{a}$, Ulrik B. Henriksen ${ }^{a}$

${ }^{a}$ Department of Chemical and Biochemical Engineering, Technical University of Denmark, 2800 Kgs. Lyngby, Denmark

${ }^{b}$ Bioenergy and Thermal Power, Ørsted, Nesa Allé 1, 2820 Gentofte, Denmark

*Corresponding author. Tel.: +4593511606. E-mail address: marv@kt.dtu.dk (M. Masche)

\begin{abstract}
This study assesses the changes in physical properties (particle size, shape, density) of Austrian pine (softwood) and European beech (hardwood), as they are mechanically processed from wood chips to pellets and then to milled pellets. A series of semi-industrial hammer mills and a semi-industrial pellet mill were used. The specific pelletizing and grinding energy, as well as the pellet mill and hammer mill capacity, were determined. Size, shape, and bulk density of the wood particles obtained at each processing step were studied. The pellet quality was analyzed according to international standards. Results show that the pelletization modifies the internal pellet particle shape and length due to the breakage of particles across their longest dimension, leading to more circular and less elongated particles. However, the particle width was nearly unaffected, indicating a directional fracture behavior for wood particles during pelletization. The particle breaking effect was more dominant for beech particles. Beech contained a lower amount of extractives than pine that led to higher specific pelletizing energy. In addition, beech
\end{abstract}


pellets had a lower quality concerning durability and density. Relationships between specific grinding energies and characteristic product particle sizes were also determined. E.g., the specific energy for grinding pine pellets was about $10 \mathrm{kWh} / \mathrm{t}$ oven-dry wood for a characteristic product size of $0.8 \mathrm{~mm}$, while grinding beech pellets required about $7 \mathrm{kWh} / \mathrm{t}$ oven-dry wood for a characteristic product size of $0.6 \mathrm{~mm}$. The study concludes that less energy is needed to pelletize pine than beech under the same processing conditions, but more energy is needed to mill pine than beech.

\section{Keywords}

Wood pellet; wood chip; hammer mill; pellet mill; specific energy; particle size.

\section{Introduction}

Denmark has a long history of encouraging the use of biomass in heat and power production. In 1993, a binding biomass agreement led to the use of biomass in several combined heat and power plants [1]. Today, wood pellets play an important role in the conversion of Danish coal suspension-fired power plants into biomass operation. The use of biomass has the potential to reduce life-cycle greenhouse gas (GHG) emissions from fossil fuel-derived electricity and heat [2]. To reduce the GHG emissions in Denmark, the largest Danish energy company, Ørsted, will stop all use of coal at its power stations by 2023 [3]. Biomass consumption for energy production in Denmark is hence expected to increase from $137 \mathrm{PJ}$ in 2012 to $173 \mathrm{PJ}$ in 2020 [4]. Moreover, Danish imports of wood pellets will increase from 2 million metric tons in 2012 to over 3 million metric tons in 2020 [5].

In the field of biomass pelletization, size reduction of woody feedstock is an important processing step, as it changes the physical properties (e.g., particle size, shape, flowability, bulk 
density) of biomass. Fig. 1 shows the mechanical size reduction pathway of pellet feedstock, which includes several size reduction steps. Hammer mills are commonly used for size reduction in a pellet plant. Size reduction increases the total surface-area-to-volume ratio and the inter-particle contact points. Smaller particles improve pellet strength properties [6,7]. They also lead to more durable [8] and denser pellets due to smaller particles rearranging and flowing into void spaces between coarser particles [9]. However, pellet producers will not comminute the raw material more than needed, as grinding biomass to smaller particles requires more energy.

Generally, the energy consumption for biomass grinding depends on particle feed size, moisture content, fiber length, density, biomass type, material feed rate, and milling equipment [10-13]. Temmerman et al. [10] reported higher energy consumptions for grinding wood chips and wood pellets with higher moisture levels. For similar moisture levels, pellets needed less grinding energy than wood chips. Vasic and Stanzl-Tschegg [14] observed that the total fracture energy to split a wood sample into two halves increased with increasing moisture levels, which they attributed to a higher wood ductility. Consequently, wood drying results in lower comminution energy [11] and provides smaller particles at similar mill settings [15] due to a more brittle fracture behavior.

It has also been well-documented that the chemical structure of biomass influences its pelletizing performance and pellet quality. Softwoods with greater extractive amounts require less power for pelletizing than hardwoods due to the lubricating effect of extractives that reduces the friction in the pellet die channels [16]. However, there has been some disagreement regarding the role of extractives in the pellet quality. Nielsen et al. [17] found that biomasses 
with more extractives decreased the pellet durability, while Filbakk et al. [16] established a positive relationship between extractives and pellet durability. In addition, the combining effect of lignin and extractives appears not to be well-understood. Ahn et al. [18] observed that blending bark into the pelletizing process significantly reduced the durability of larch pellets and slightly improved the durability of tulip pellets, while lignin powder steadily increased the durability of larch and tulip pellets. In contrast, Wilson [19] concluded that the lignin content has no noticeable impact on the durability of pellets, which were produced from pure and mixed hardwood and softwood species. During densification at high temperatures, lignin passes from a glassy to a rubbery phase, which improves the binding of adjacent particles [20]. The glass transition temperature of lignin was found to vary between wood species [21] and for different moisture contents [22]. Water acts both as a binder in pellets due to hydrogen bonds between adjacent particles [23] and as a friction-reducing lubricant in the die channel [24].

For large-scale biomass suspension-firing, wood pellets need to be milled before firing in the boiler. It is often believed that wood pellets, after comminution in the existing coal mills, will be broken down to the original particle size distribution (PSD) of the feedstock before pelletizing $[25,26]$. To obtain information about the pre-densified PSD of material within fuel pellets (i.e., the internal pellet PSD), pellets are disintegrated into their constituents in water according to ISO 17830:2016 [26]. Knowledge about the physical properties of fuel particles is important for achieving an undisturbed flow inside the pneumatic conveying pipe system, and for obtaining a stable flame and high fuel burnout. The internal pellet PSD is hence an important fuel specification for industrial end users with respect to the particle combustion properties. 
The literature shows that the size reduction and pelletization of wood is a complicated process affected by the chemical, physical, mechanical, and fracture properties of wood and the equipment used. Most of the studies available only focus on one or two steps of the whole pelletization process. They mainly try to determine the pelletability of different biomass materials, optimize the operation of the pellet mill, or evaluate the resulting pellet quality and milling properties. However, to the best of the authors' knowledge, there are no studies that follow the complete mechanical processing pathway of wood. Considering that the internal PSD of wood pellets plays an essential role in determining the wood pellet quality, it is important to know how the PSD and particle shape is obtained and, furthermore, which steps are crucial in determining the particle size and shape of material within pellets. Thus, it is essential to assess the effect of each processing step on the wood particle size and shape. To achieve this objective, the present study follows the complete mechanical processing pathway of European beech (hardwood) and Austrian pine (softwood). All processing steps are included and carefully examined to provide knowledge of how pelletization and comminution operations alter the physical properties of wood particles. The results of this study will be relevant to pellet producers, who want to produce pellets of desirable quality for use in suspension-fired power plant boilers. Furthermore, studies focusing on pellet comminution usually lack the process history of pellets. Milling studies commonly lack information about the initial feed material characteristics. This study hence includes a thorough characterization of the chemical and physical properties of the wood chips utilized. 


\section{Materials and methods}

\subsection{Wood chip preparation}

About 50-year-old European beech (Fagus sylvatica) trees and ca. 40-year-old Austrian pine (Pinus nigra) trees from Central Zealand (Denmark) were used in this work. The composition of the raw lignocellulosic materials was analyzed according to the standard analytical procedures provided by the National Renewable Energy Laboratory [27,28]. The trees were limbed, debarked, and turned into logs of wood (Fig. 2). The bark from the beech stem wood was removed nearly completely, while the pine stem wood showed some bark leftovers that may have resulted in a higher extractives content [29]. The logwood was chipped using a mobile wood chipper (DH 811 L, Doppstadt GmbH, Germany). Chipping represents the first size reduction step that turns the logwood into smaller pieces that can be handled easier by downstream milling operations. The initial moisture content of the logwoods was about 53 wt. $\%$ for pine and $36 \mathrm{wt} \% \%$ for beech.

\subsection{Pellet feedstock processing}

The process flow for pelletizing wood at the pellet plant is the same as shown in Fig. 1. First, the fresh wood chips underwent coarse milling in a semi-industrial hammer mill (Optimill 500, Andritz AG, Austria) powered by a $110 \mathrm{~kW}$ motor and equipped with a $15 \mathrm{~mm}$ screen (Fig. 3). The purpose of coarse milling was to produce a more homogenous material that could be dried more evenly. The coarse milling was followed by drying in batch mode on a perforated steel floor, with hot air passing through. The coarse grinds were dried to a moisture content of about 12 wt.\%. The dried material was then milled in a hammer mill (Multimill 450, Andritz AG, Austria) powered by a $90 \mathrm{~kW}$ motor and equipped with a $4 \mathrm{~mm}$ screen, which is typically used 
for the production of $6 \mathrm{~mm}$ pellets [30]. The goal of fine milling is to achieve the desired PSD required for pelletizing.

\subsection{Pellet production, characterization, and milling}

Before pelletizing, the fine grinds were transported to a cascade mixer, where they were conditioned by hot steam to soften the lignin in the wood. The lignin softening enables fine grinds pelletization without adding binders, as the lignin serves as a natural binder to form solid interparticle bridges due to thermoplastic flow [31]. Pellets from the fine grinds were produced using a semi-industrial pellet mill (PM615W, Andritz AG, Austria) powered by a $160 \mathrm{~kW}$ motor. The pellet mill comprises a stainless steel, rotating perforated ring die with seven rows of $6 \mathrm{~mm}$ die channels (Fig. 4). Fine grinds are distributed over the inner surface of the ring die. Two rotating rollers press the fine grinds through the die channels, where they are compacted due to friction between the wood particles and the die wall. For the pelletization of pine, a die channel length of $50 \mathrm{~mm}$ was used, resulting in a die aspect ratio (ratio of channel length to channel diameter) of 8.3. However, to produce beech pellets of acceptable quality, the die aspect ratio had to be changed to 5.8 (die channel length of $35 \mathrm{~mm}$ ). The need for a lower aspect ratio when pelletizing hardwoods compared to softwoods was also found in the literature [32]. After pelletizing, the hot pellets were cooled by ambient air in an updraft cooler and sieved using a $3.15 \mathrm{~mm}$ screen to remove fines.

Pine and beech pellets were then characterized in triplicate according to international standardized methods, and their quality was assessed by ISO 17225-2:2014 [33], which grades wood pellets for industrial use from I1 to I3. Wood pellets of property class I1 are considered as pellets of the highest quality, while I3 pellets are considered as pellets of the lowest quality. 
The mechanical durability of pellets was measured using a rotating tumbling box according to EN ISO 17831-1:2015 [34], which predicts the amount of fines produced during handling and transportation processes. A sample of $500 \mathrm{~g}$ was tumbled at $50 \mathrm{rpm}$ for 500 rotations. The durability is then calculated from the mass of sample remaining after separation of abraded particles.

Finally, pellets were comminuted in the hammer mill using a $4 \mathrm{~mm}$ screen that was also used for fine milling. The feeder motor frequency was lowered from $55 \mathrm{~Hz}$ to $20 \mathrm{~Hz}$, which had the effect of reducing the feed rate to $64 \%$ of the previous value in order to avoid overloading the mill.

\subsection{Measurement of specific grinding and pelletizing energy consumption}

The milling and pelletizing equipment include a wattmeter to measure the instantaneous power consumption (W). The operating time (h), current (A) and feeding amount (kg) were recorded. A balance under the screw feeder measured the wood feed amount. From these parameters, the capacity in $\mathrm{kg} / \mathrm{h}$ and total specific energy consumption $(S E C)$ in $\mathrm{kWh} / \mathrm{t}$ for grinding and pelletizing operations were calculated. The $S E C$ was expressed as follows:

$\mathrm{SEC}=\int_{o}^{t} \frac{P}{m_{\text {feed }}} d t$

Where $P$ represents the total, instantaneous power $(\mathrm{W})$ consumed by the mill or pelletizer. $m_{f e e d}$ is the amount of wood to be milled (or pelleted). SEC was corrected to a dry wood basis (DW) to allow the comparison among woods with different moisture contents. The idle power consumption of the hammer mill and pellet mill was not measured, as it was considered necessary to operate the milling and pelletizing equipment. Hence, the calculated values for $S E C$ also include the energy required to run the mill empty (no load). 


\subsection{Wood characterization}

\subsubsection{Moisture analysis}

All moisture contents reported in this study were determined in triplicate by drying the samples up to $16 \mathrm{~h}$ in a drying oven at $105 \pm 2^{\circ} \mathrm{C}$ according to ISO 18134-1:2015 [35]. The moisture content was then calculated based on the mass decrease during drying.

\subsubsection{Bulk density measurements}

The loose-packed bulk density was determined by pouring the sample into a funnel located at the top of a calibrated vessel of 5 liters. A known sample mass was added to the vessel, and the sample volume measured. This procedure was done in triplicate.

\subsubsection{Wood size and shape characterization}

A vibrating sieve shaker (AS 200 control, Retsch Technology GmbH, Germany) was used to analyze the PSD of the different wood samples. The characteristic sieve size $\left(d_{\text {sieving }}\right)$ is defined based on the square-hole sieves as the minimum aperture size in mm through which each wood particle can pass. For wood chips, the stack comprised nine square-hole sieves with a diameter of $200 \mathrm{~mm}$, and aperture sizes of 1.4, 2.8, 5.6, 7.1, 10, 12.5, 16, 20 and $25 \mathrm{~mm}$, mounted on a collecting pan. For coarse grinds, aperture sizes of 0.5, 1.0, 1.4, 2.0, 2.8, 4.0, 5.6, 7.1, and $10 \mathrm{~mm}$ were used. The sieve stack for the analysis of fine grinds, disintegrated wood pellets, and milled wood pellets included sieves of $0.25,0.5,1.0,1.4,2.0,2.8$, and $3.15 \mathrm{~mm}$. Samples

of about 50-150 g were tested. An electronic balance (EW-N, KERN \& SOHN GmbH, Germany) weighed the individual sieves and pan before and after sieving. This information was converted into a cumulative (undersize) weight distribution versus $d_{\text {sieving. }} . d_{\text {sieving }}$ represents the 
percentage of sample passing through each sieve. Sieve analysis was run for 10 min with $1 \mathrm{~mm}$ amplitude and performed in triplicate.

The wood chips were categorized into eight size classes according to the sieve stack used. Several runs of sieve analysis were performed to get a representative number of particles in each size class. Owing to the various shapes of wood chips, all chip dimensions were reported as means of at least a hundred measurements. Assuming that wood chips can be represented by flat cuboids (Fig. 5), their three dimensions were manually measured using a digital caliper with an accuracy of $0.01 \mathrm{~mm}$. The length represented the longest distance between two parallel tangents restricting the particle along the grain direction. The particle width represented the second longest distance perpendicular to the length (and thus perpendicular to the grain direction). The thickness referred to the third longest distance perpendicular to both length and width. Measurements of the dimensions were performed on air-dried samples, as moisture differences between pine and beech wood chips would reduce the measurement accuracy. The wood chip weight was measured using a precision balance with an accuracy of $0.01 \mathrm{~g}$. The specific chip density can then be calculated as the ratio between weight and volume. With the measurements of all three particle dimensions, the degree of elongation and flatness of a wood chip particle can be classified according to [36]:

$$
\begin{aligned}
& \text { Elongation }=\frac{\text { Chip width }}{\text { Chip length }} \\
& \text { Flatness }=\frac{\text { Chip thickness }}{\text { Chip length }}
\end{aligned}
$$

To complement the sieve analysis, the size and shape of fine grinds, disintegrated pellets, and milled pellets were also analyzed using a Camsizer ${ }^{\circledR} \mathrm{X} 2$ (Retsch Technology GmbH, Germany) 
operated in X-Jet mode for air pressure dispersion. Measurements were performed in triplicate. The PSD is presented as a cumulative (undersize) volume distribution versus $d_{c, \min } . d_{c, \min }$ represents the narrowest maximum chord length of a 2D particle projection measured from all measurement directions. Recent studies [37,38] suggest that $d_{c, \min }$ gives close results to sieving data. Two shape factors provided by the Camsizer ${ }^{\circledR} \mathrm{X} 2$ software were used to characterize the particle shape; elongation ratio (width-to-length ratio) and circularity. The elongation ratio (ER) is equal to one when particles are circles and squares, and it is defined as follows [39]:

$E R=\frac{d_{c, \min }}{d_{F e, \max }}$

Where $d_{F e, \max }$ refers to the maximum Feret diameter or maximum caliper diameter that is close to the true particle length [40]. The circularity $(C)$ indicates how closely the 2D particle projection resembles a circle. The circularity defined by Cox [41] is described as follows:

$C=4 \cdot \pi \cdot \frac{A_{\text {particle }}}{P_{\text {particle }}^{2}}$

Where $A_{\text {Particle }}$ and $P_{\text {Particle }}$ refer to the particle projection area and the particle perimeter, respectively. An ideal perfect circle has a circularity value of 1 .

\subsection{Data analysis}

The Rosin-Rammler-Bennet-Sperling (RRBS) model is used to describe the PSD of wood. It is

a two-parameter distribution function expressed as a cumulative percent (undersize) distribution, which was found to be suitable to describe the PSD of wood pellet feedstock [42]. The RRBS equation is [43]:

$R(d)=100-100 \cdot e^{-\left(\frac{d}{d^{*}}\right)^{n}}$ 
Where $R(d)$ is the cumulative percent (undersize) distribution of material finer than the particle size $d, d^{*}$ is the characteristic particle size defined as the size at which 63,21\% of the PSD lies below, and $n$ is the distribution parameter. The $d^{*}$ also characterizes the fineness of the wood material. The 10th percentile (D10) and the 90th percentile (D90) of the cumulative undersize distribution were used to determine the distribution span, (D90-D10).

Von Rittinger's comminution law is used to predict the energy consumption for grinding wood. Although Von Rittinger's law was developed for the mineral industry, recent studies $[10,37,44]$ suggest its applicability to determine the energy demand for grinding lignocellulosic biomass. An advantage of this law is the application of the size reduction ratio to normalize the effect of the initial feed particle size. Von Rittinger stated that the energy required for size reduction is directly proportional to the new surface area produced [45], and he defined the relationship as follows [46]:

$S G E C=K_{R}\left(\frac{1}{d_{p}}-\frac{1}{d_{f}}\right)$

Where $S G E C$ is the specific grinding energy consumption (in $\mathrm{kWh} / \mathrm{t}$ ), $d_{p}$ (in $\mathrm{mm}$ ) is the characteristic particle size of the milled product, and $d_{f}$ (in $\mathrm{mm}$ ) is the characteristic particle size of the feed material. In the case of pellet comminution, $d_{f}$ is the characteristic particle size of the disintegrated pellet material. $K_{R}\left(\right.$ in $\left.\mathrm{kWh} \mathrm{mm} \mathrm{t}^{-1}\right)$ is the material characteristic parameter or Von Rittinger constant, which is a measure of the wood grindability. 


\section{Results and discussion}

\subsection{Initial wood characterization}

The chemical analysis shows, as it is typical for softwoods [47], that pine has a higher Klason lignin amount than beech (Table 1). On the other hand, beech comprises more carbohydrates, including glucose, a good indicator of the biomass cellulose content, and hemicelluloses, consisting of monomers like xylose, mannose, glucose, galactose, arabinose, rhamnose, and uronic acids. Mannose is the most common monomer in softwoods, while xylose is more prevalent in hardwoods. Pine also has a much higher content of water- and ethanol-soluble extractives than beech. The sum of the chemical composition of beech is lower than $100 \%$ unlike pine, probably because beech can contain a fair bit of acetyl groups [48] that are not accounted in the chemical analysis.

The wood chips produced are presented in Fig. 6. On average, sieve analysis showed nearly similar size distributions for pine and beech chips. In Fig. 7, the caliper-measured dimensions of pine and beech chips in the respective sieve size classes are shown. Similar to the sieve analysis, also the caliper-measurements show similar size distributions for pine and beech chips. Comparing Fig. 6. and Fig. 7, the sieve size distribution is mainly determined by the wood chip width, which confirms previous findings [11,49]. The sieve analysis does not represent the real length and thickness of wood chips due to their needle-like shape. The caliper measurements show that all three dimensions of pine and beech chips significantly $(\mathrm{p}<0.05)$ increase in a linear manner with increasing sieve fraction. The chip thickness is significantly smaller than the other two chip dimensions, and wood chips in smaller sieves are more regular regarding their dimensions than those retained on coarser sieves. 
The elongation and flatness of wood chips are shown in Supplementary Fig. S1. Smaller chips were a little more elongated than coarser wood chips, which was also observed by Lanning et al. [50] for chips produced from whole trees. The chip flatness ratio shows that, regardless of their length, both wood chips keep nearly the same flat shape. That means a flatness ratio of 0.23 for pine chips and 0.17 for beech chips. These findings are probably linked to the wood fracture mechanism during chipping, which is specific to the individual wood species. The chip length is controlled by the feed rate of the conveyor floor and the mesh size of the screening basket of the mobile chipper. The thickness and width of the wood chips are more a result of how wood fractures due to mechanical stress. As shown in Supplementary Fig. S2, pine chips are thicker than beech chips, but beech chips have a higher specific density than pine. Regardless of the chip length, beech chips are significantly denser (ca. $390 \mathrm{~kg} / \mathrm{m}^{3}$ on average) than pine chips (ca. $230 \mathrm{~kg} / \mathrm{m}^{3}$ ). The results are in good agreement with Twaddle's [51] result, who observed that the chip thickness is inversely proportional to the specific density, i.e., Douglas fir chips were thicker than denser beech chips.

\subsection{Two-stage size reduction}

The wood chips went through a two-stage milling process, including coarse and fine milling in a series of hammer mills. Before fine milling, the fresh coarse grinds were dried. The moisture contents and the PSD of milled beech and pine products are shown in Supplementary Fig. S3. As expected, fine milling produced smaller particles and a narrower size distribution span than coarse milling. The two-stage milling process resulted in a higher size reduction and a greater portion of fines for beech than for pine. For instance, the amount of particles below $1 \mathrm{~mm}$ increased from 27 to $87 \%$ for beech and from 4 to $60 \%$ for pine, from the first to the second 
milling stage. Drying the coarse grinds can be expected to favor the production of fines for the fine milling stage [15].

Table 2 presents the results for the milling performance of pine and beech in a series of hammer mills. The first milling stage produced characteristic particle sizes of $2.5 \mathrm{~mm}$ for beech compared to $4.0 \mathrm{~mm}$ for pine. The second milling stage led to characteristic particle sizes of $0.6 \mathrm{~mm}$ for beech and $1.0 \mathrm{~mm}$ for pine. Thus, the second milling stage reduced the characteristic particle size by about $75 \%$ and provided a product PSD that can be used in a pellet mill. Fine milling caused an additional drying of the material and reduced the initial moisture of coarse grinds (12 wt.\%) by ca. 30\% (Supplementary Fig. S3). The results are in good agreement with previous observations $[52,53]$, where it was observed that decreasing the hammer mill screen size increased the moisture reduction during milling due to both a longer particle retention time in the mill and a larger particle surface area produced [53]. In addition, the friction between particles and between particles and the equipment also causes an energy loss by heat dissipation, which also results in moisture loss.

The specific energy consumption for coarse milling was higher for pine (12.6 kWh/t DW) than for beech chips $(8.1 \mathrm{kWh} / \mathrm{t} \mathrm{DW})$, as shown in Table 2 . The higher moisture content for pine chips probably increased the ductility of wood [14] and thus the grinding energy effort. Pine chips were also thicker than beech, which affects the grinding energy, as more energy is required to fracture a thicker wood sample [54]. The fine milling increased the grinding energy input approximately by a factor of four for pine and a factor of five for beech. On average, fine milling beech required about $12 \%$ less energy and led to a $9 \%$ higher mill capacity than pine. 
The higher specific energy consumption for milling pine compared with beech is in line with previous findings $[10,12]$.

\subsection{Pellet production and pellet characterization}

Table 3 shows the quality parameters of the produced beech and pine pellets, as well as the pelletizing performance. Regarding the determination of the internal PSD of pellets, the ISO procedure 17830:2016 worked well for pine pellets. For beech pellets, the ISO procedure was not able to separate all individual wood particles that constitute a pellet. As a consequence, agglomerated particles were observed after the hot water disintegration procedure. This resulted in an overestimation of larger particles. Higher attractive forces between smaller particles due to van der Waals interactions [55] may explain the greater tendency for beech particles to form agglomerated particles during disintegration in hot water. Attempts to break up the agglomerated particles by using a sieving amplitude of $3 \mathrm{~mm}$, as suggested by Jensen et al. [56], did not lead to a considerably better particle separation (see Supplementary Fig. S4). However, adding, again, hot water to the dried disintegrated beech pellet particles was found to be the best method to achieve a better particle separation. The pellet disintegration results in Table 3 indicate that pine pellets contain $20 \%$ fewer particles below $1 \mathrm{~mm}$ compared to disintegrated beech pellets.

After pelletizing, beech pellets had a lower moisture content than pine pellets. This could be explained by higher friction in the pellet die during pelletization of beech due to its lower extractive content [17]. Temperature measurements of the steam produced during the pellet production process corroborate the observations made. Pelletizing beech led to a higher temperature $\left(100^{\circ} \mathrm{C}\right)$ than pelletizing pine $\left(70-75^{\circ} \mathrm{C}\right)$. Also, the higher amount of fines in beech 
sawdust (ca. $50 \%$ below $0.5 \mathrm{~mm}$ ) can increase the friction in the die [57]. Higher friction generates heat that will be quickly transferred to the beech particles causing further drying. This can explain the slightly burnt surfaces on beech pellets that were not observed on pine pellets (Supplementary Fig. S5). The lack of water in beech pellets probably reduces the binding effect of water, which can impact the inter-particle bonding and thus the pellet durability [24].

The bulk density for pine and beech pellets falls within the range of previously reported values (i.e., $498-649 \mathrm{~kg} / \mathrm{m}^{3}$ ) [58]. However, only pine pellets comply with the international standard for industrial pellets, ISO 17225-2:2014 [33], that requires a bulk density equal to or above $600 \mathrm{~kg} / \mathrm{m}^{3}$. The lower bulk density of beech pellets can be explained by the longer pellets (compared to pine pellets), lower moisture content, and lower specific pellet density.

Pine pellets showed higher specific pellet densities than beech pellets, probably due to the higher die aspect ratio used during their production which caused a higher compaction and pressure build-up in the press channels. Thus, pelletizing increased the specific density compared to beech and pine wood chips by about $190 \%$ and $400 \%$, respectively. The specific pellet density as a pellet property is not included in ISO 17225-2:2014 [33], but according to DIN 51731 the specific pellet density should be between 1000 and $1400 \mathrm{~kg} / \mathrm{m}^{3}$ [59]. Judging from the results, the pellet density of beech and pine pellets falls within that range.

Regarding the durability, pine pellets are more durable than beech pellets, indicating a higher ability to resist abrasion during handling and transportation and thus a lower risk of fires and explosions during handling and shipping [60]. According to the ISO 17225-2:2014 standard [33], pine pellets comply with the requirements for class I1, while beech pellets fail to comply with the requirements of the lowest pellet class (i.e., I3) due to their lower bulk density. 
Differences in durability are a result of the combined effect of die aspect ratio, moisture, extractives, and lignin content. In a previous study [16], it was observed that higher extractives and lignin content resulted in a binding effect, increasing the degree of particle adhesion, and thus better durability. Also, the broader distribution of particle sizes for pine may enhance the pellet quality [57]. It was shown that finer particles fill in the voids formed among larger particles, hence producing denser and more durable pellets [9].

The capacity and energy demand for pelletizing wood are important measures of the pellet production costs. On average, the pellet mill showed higher capacity and significantly lower energy requirement for pelletizing fine pine grinds than for fine beech grinds (Table 3). The results of the chemical composition for pine showed an eightfold higher amount of extractives (such as wood resin) compared to beech (Table 1). Nielsen et al. [61] reported that biomasses with a lesser amount of these extractives increased the energy required to compress the fine grinds, to force the compressed material into the pellet die channels, and to force the flow of compressed material layer through the die channels. Hence, the higher extractive content in pine probably lubricated the die channels, leading to higher production capacity and lower energy input for pelletization compared to beech.

\subsection{Pellet comminution}

Table 2 also summarizes the milling performance for beech and pine pellets. Compared to fine milling, pellet comminution shows a significantly lower $S G E C$, indicating better grindability of the pellets. Hence, during pelletizing, the bond formation between adjacent particles creates

a densified material that is easier to fracture than the non-densified coarse grinds. However, it has to be noted that the higher throughput (capacity) for pellet comminution probably favors 
lower specific energy compared to fine milling. It is difficult to compare the specific energy data with other pellet milling studies, which used lab-scale hammer mills [10,62].

Similar to fine milling, a lower $K_{R}$ value for milling beech pellets was found, indicating a lower milling energy consumption compared to pine pellets. This can be explained by the less durable beech pellets or the finer internal beech pellet particles or. Beech particles may have a shorter residence time in the milling chamber, as they have a higher probability to pass through the $4 \mathrm{~mm}$ hammer mill screen. However, coarser pine particles probably have a longer residence time that increases the possibility of more breaking actions induced by the hammers, entailing a higher grinding energy consumption. In addition, the higher moisture level in pine pellets probably resulted in a higher ductility [14] and hence the specific energy. The higher extractives content in pine may also affect the specific energy. It was reported that extractives could interfere with the mechanical processing of wood [11]. For example, resins can build up on cutting tools, which will become dull [63].

The different qualities of beech and pine pellets seemed not to affect the hammer mill capacity, as a grinding capacity of ca. $3 \mathrm{t} / \mathrm{h}$ was obtained in both cases. Interestingly, the comminution of the pellets led to a similar size reduction ratio of about 0.2 , regardless of the differences in the feed material. During hammer milling of the pellets, a drying effect was observed (cf. Table 3 and Table 4). The drying effect was slightly higher for milling beech pellets than for milling pine pellets probably because of the greater surface area of beech particles, which facilitates better moisture evaporation inside the hammer mill chamber. 


\subsection{Physical properties of fine grinds, disintegrated pellets, and milled pellets}

The PSDs of milled pellets, disintegrated pellets, and fine grinds versus the particle width $\left(d_{c, \text { min }}\right)$ and the particle length $\left(d_{F e, \max }\right)$ determined by digital image analysis are shown in Fig. 8A and Fig. 8B, respectively. Table 4 summarizes the physical properties of the different wood particles. The comminution of beech and pine pellets in a hammer mill shifted the PSD to the left in both Fig. 8A and Fig. 8B, indicating a reduced width and length compared to internal pellet particles. This final milling step resulted in characteristic particle widths and lengths of $0.68 \mathrm{~mm}$ and $1.47 \mathrm{~mm}$ for milled beech pellets and $0.90 \mathrm{~mm}$ and $1.94 \mathrm{~mm}$ for milled pine pellets, respectively. Thus, the final milling step did not only disintegrate pellets into constituent internal particles but achieved some size reduction of the particles. This study hence provides further evidence for both structural pellet breakdown and size reduction of the internal pellet particles during pellet comminution, which Temmerman et al. [10] assumed merely based on energy consumption data. Fig. 8A shows that the size reduction in width was larger for pine pellet particles than for beech pellet particles. However, beech particles always show a finer PSD than pine particles, probably due to the different breakage mechanism of softwoods and hardwoods. The latter ones are characterized by the presence of vessel elements (pores), while softwoods have none. These vessel elements affect the wood crack path, i.e., the crack may enter the vessel element [64] and crack propagation becomes easier [65], thus producing smaller particles. Comminuting pellets produced a narrower (uniform) particle size range compared to fine grinds and disintegrated pellets. Williams et al. [66] also reported an enhanced uniformity for comminuted pellet particle sizes compared to the pre-densified material. It is hence concluded that pellet comminution is accompanied by a reduction of the coarse particles to 
smaller sizes, which leads to a steeper and narrower size distribution curve. Regarding the particles length $\left(d_{F e, \max }\right)$ in Fig. $8 \mathrm{~B}$, on average, all beech samples have more particles with a length below $1 \mathrm{~mm}$ than pine samples, indicating that beech particles are shorter than those from pine. Differences can be linked to the wood cell wall structure. The shorter length for beech fibers is typical for hardwoods compared to softwoods [67].

The 2D derived shape factors are presented in Fig. 9. The changes in particle shape from fine grinds to disintegrated pellets to milled pellets reflect changes occurring during fine grinds densification in the pellet mill and pellet comminution in the hammer mill, respectively. The overall trend is that pine and beech particles become rounder and less elongated with the number of processing steps, including pelletization, and pellet comminution. However, the change in shape from disintegrated pellet particles to milled pellet particles is smaller than from fine grinds to disintegrated pellet particles. Fig. 9 shows that the circularity increases with decreasing particle size, indicating that the finer particles are more circular than coarser particles. This finding concurs well with Tannous et al.'s study [68], who observed a similar trend for milled Douglas fir particles. Due to the anisotropic cell wall structure of wood, beech and pine particles show a needle-like shape, indicated by low elongation ratios. On average, fine beech grinds have lower elongation ratios $(E R=0.38)$ than fine pine grinds $(E R=0.42)$. As mentioned previously, lower elongation ratios were also found for beech chips compared to pine chips. For coarser particles, the elongation ratios between the two wood species differ largely. For smaller particles, the degree of elongation is more similar, as the structure difference between biomasses seems to reduce with decreasing particle size [69]. 
Regarding the effect of the pellet mill on the particles, it was observed that it does not alter the particle width, as differences between the characteristic particle size of fine grinds and disintegrated pellets are negligible (Fig. 8A). This result concurs well with Trubetskaya et al.'s [70] findings. However, it reduces the particle length for both samples, e.g., the amount of particles shorter than $1 \mathrm{~mm}$ is $23 \%$ for fine beech grinds and $30 \%$ for disintegrated beech pellet particles (Fig. 8B). For pine, the amount of particles shorter than $1 \mathrm{~mm}$ increases from $12 \%$ for fine grinds to $16 \%$ for disintegrated pellet particles. The small increase in shorter particles after the pellet mill suggests that particles break across their largest dimension in the process of pellet formation, indicating a directional particle breakage behavior. During pelletizing, wood particles are forced into the die channels by the two rollers that move due to the friction and movement of the rotating ring die. Hence, the particle breakage may be explained by shearing of wood particles occurring between the rollers and the rotating die. The smaller increase in shorter particles was larger for beech during pelletizing. Due to their lower extractives content, beech particles will show greater friction in the roller-pellet die contact area, which probably favors a more brittle fracture behavior of beech particles. Vasic and Stanzl-Tschegg [14] showed that pine has a more ductile fracture response than beech so that the rigid beech is more likely to break during stress. The change in particle length inevitably affects the internal pellet particle shape (Fig. 9). In particular, the average circularity for pine increases from 0.41 (fine grinds) to 0.50 (disintegrated pellets) and from 0.45 (fine grinds) to 0.55 (disintegrated pellets) for beech. In the same way, the elongation ratio increases from 0.41 (fine grinds) to 0.48 (disintegrated pellets) for pine, and from 0.38 (fine grinds) to 0.51 (disintegrated pellets) for beech. The final pellet milling step had only a negligible effect on the wood particle shape. Thus, changes in circularity and elongation ratio between fine grinds and internal pellet particles 
are directly related with the length reduction observed on disintegrated pellet particles compared to fine grinds. Hence, the pelletizing process modified the elongated wood particle shape of fine grinds more than the subsequent pellet milling step in the hammer mill.

Table 4 presents loose bulk density values for the various wood types. On average, all beech samples show higher bulk densities than pine due to a higher particle density and smaller particles. Smaller beech particles can be embedded in the voids between larger particles, thus favoring a better packing structure. Milling wood pellets leads to a further reduction of the interparticle gaps due to the production of finer particles that allow better packing ability [71]. Thus, final bulk densities of milled pellet product of ca. $400 \mathrm{~kg} / \mathrm{m}^{3}$ for beech and $280 \mathrm{~kg} / \mathrm{m}^{3}$ for pine were obtained. Differences in bulk density may also be linked to the different particle shape. Fine grinds comprise more elongated and less circular particles than milled pellets, which can cause mechanical interlocking between particles and an increase in porosity of the bulk solid [72]. This leads to less compaction and lower bulk density. Rezaei et al. [62] observed a similar trend for needle-like milled chip particles compared to more spherical milled pellet particles.

\subsection{Implications for wood pellet producers and power plant operators}

For pellet producers and power plant operators, the energy for mechanical processes (i.e., size reduction and pelletization) has to be minimized to achieve optimal process efficiencies. Fig. $10 \mathrm{~A}$ and Fig. 10B plot the SGEC versus the size reduction (comminution) ratio of Von Rittinger's comminution law and the $S G E C$ versus the characteristic product particle size, respectively. A strong power law relationship $\left(R^{2}=1.00\right.$ for pine and $R^{2}=0.90$ for beech) was found between $S G E C$ and the size reduction ratio. Fine milling represents the most energyconsuming milling process in both cases. Milling beech requires less energy, leads to a higher 
size reduction ratio, and produces finer particles than pine. However, higher energy is required to pelletize beech than pine.

To assess how much energy of the actual energy value of the wood is used for milling and pelletizing operations, the ratio of the specific energy consumption for milling (or pelletizing) to the net calorific value of the oven dry matter $\left(N C V_{d}\right)$ was determined (Table 5). It should be stated that the energy required for milling and pelletizing is electrical energy, which is inherently more valuable than thermal energy (heat). Generally, milling and pelletizing represent only a little proportion (between 1.9 and 2.9\%) of the $N C V_{d}$. For beech, pelletizing energy represents the highest proportion of $N C V_{d}$, which is almost three times as much as for pine. The lack of extractives can probably explain why beech is more difficult to pelletize than pine. Thus, to facilitate the pelletizing process and enhance the pellet quality, pellet producers should pelletize beech mixed with pine or use binders such as brewers spent grains [32]. Due to the better grindability (i.e., the lower grinding energy) of beech pellets, switching to beech pellets will slightly improve the overall power plant efficiency and also provide finer fuel particles for suspension-firing.

\section{Conclusions}

This study investigated the physical changes occurring during the mechanical processing of beech and pine trees into chips, pellets and milled pellets. The experimental data provide valuable new knowledge of how pelletizing and hammer-milling operations modify the physical properties (size, shape, density) of beech and pine. The following conclusions can be drawn from the experimental study: 
- The pelletizing process alters the shape and length of the wood particles. There is a reduction in the particle length during pelletizing, which results in higher particle circularity and elongation (width-to-length) ratio values. The average elongation ratio for beech particles increased from 0.38 (fine grinds) to 0.51 (disintegrated pellets) to 0.52 (milled pellets). In comparison, pine particles increased in elongation from 0.42 (fine grinds) to 0.48 (disintegrated pellets) to 0.49 (milled pellets).

- Milling beech produced more fines than pine in all milling steps. For practical milling operations, beech wood requires less energy for milling than pine.

- The relationship between specific grinding energy for grinding wood and the size reduction ratio of Von Rittinger's comminution law followed a power law. Von Rittinger's law can thus be applied to predict the energy required to grind wood chips, coarse grinds, and wood pellets.

- Sieve analysis represents well the width of wood particles, but not the particle length. Digital image analysis allows direct size and shape measurements and provides more detailed data than traditional sieve analysis.

- Rosin-Rammler-Bennet-Sperling characteristic particle sizes of the milled wood chips, milled coarse grinds, and milled wood pellets are smaller than the hammer mill screen opening.

- Pelletizing beech requires more energy than pine. This behavior is attributed to a lower extractives content in beech. 
- Beech pellets are more difficult to disintegrate in water following the standard procedure ISO 17830:2016. In that case, it is recommended to perform the disintegration procedure twice.

- The wood bulk densities are sensitive to the particle size, shape, and moisture content. Bulk densities for milled beech pellets featuring finer, more circular, and less elongated particles were higher than those of coarser, less circular, and more elongated milled pine pellets.

\section{Nomenclature}

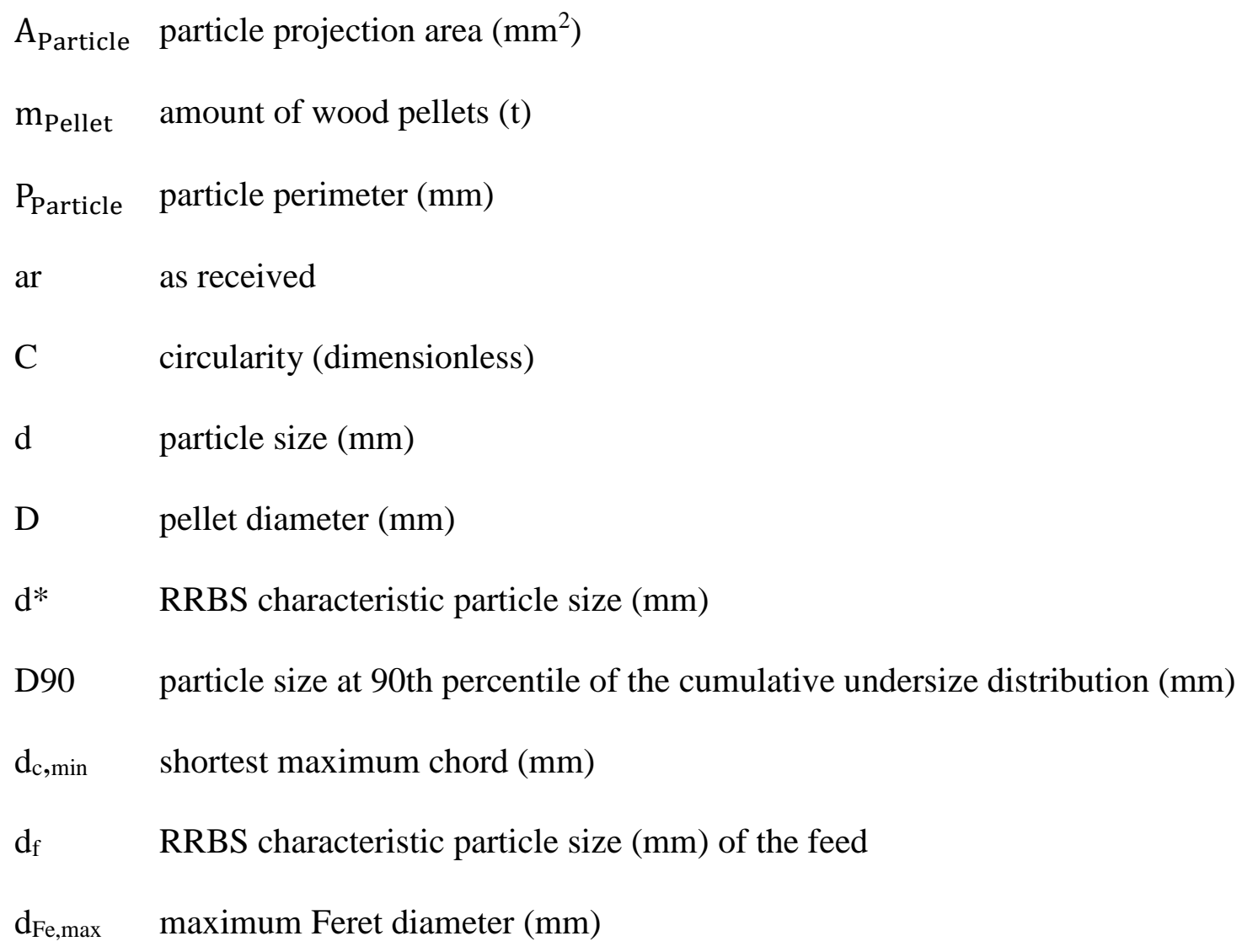




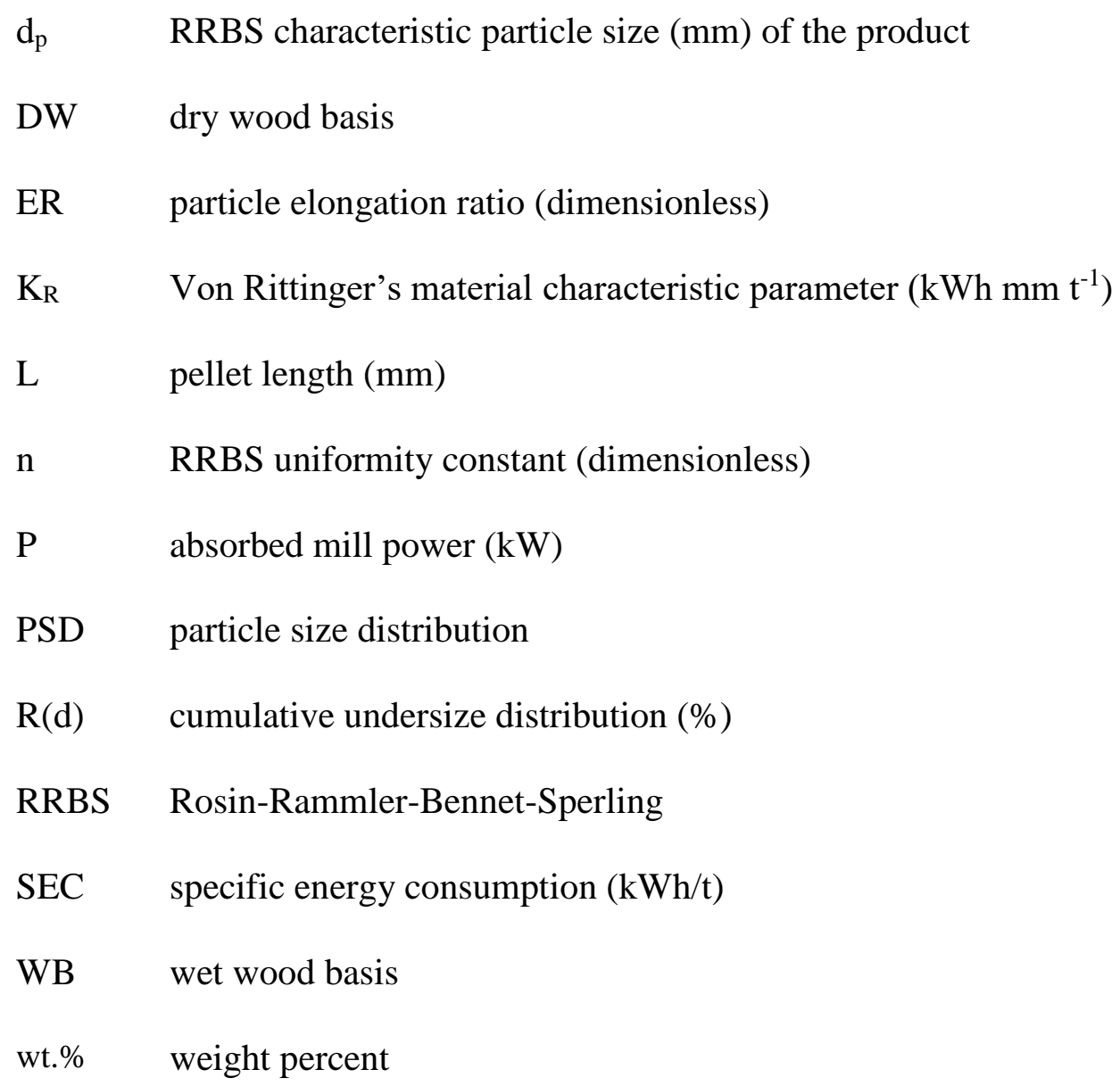

\section{Acknowledgements}

The authors thank Energiteknologiske Udviklings- og Demonstrationsprogram (EUDP) for the financial support received as part of the ForskEL project "AUWP - Advanced Utilization of Wood Pellets" (Project number: 12325). The authors are also grateful both to Bregentved Estate for providing the wood species and Danish Technological Institute (DTI) for performing the pelletizing and milling tests.

\section{Appendix A. Supplementary data}

Supplementary data associated with this article can be found in the online version. 


\section{References}

[1] J.S. Gregg, S. Bolwig, O. Solér, L. Vejlgaard, S.H. Gundersen, P.E. Grohnheit, I.T. Herrmann, K.B. Karlsson, Experiences with biomass in Denmark Systems, (2014).

[2] M.D. Staples, R. Malina, S.R.H. Barrett, The limits of bioenergy for mitigating global life-cycle greenhouse gas emissions from fossil fuels, Nature Energy. 2 (2017). doi:10.1038/nenergy.2016.202.

[3] The Ørsted Way Let's create a world that runs entirely on green energy, Ørsted. (2017). https://orsted.com//media/Aarsrapport2017/Orsted_report_Summary_2017_Final_EN (accessed June 1, 2018).

[4] From sustainable biomass to competititve bioenergy, State of Green. (2015). https://stateofgreen.com/en/uploads/2015/11/From-Sustainable-Biomass-toCompetitive-Bioenergy.pdf (accessed May 24, 2018).

[5] Usda Staff, The Market for Wood Pellets in Denmark, (2013) 3-5. http://gain.fas.usda.gov/Recent GAIN Publications/The Market for Wood Pellets in Denmark_The Hague_Denmark_11-5-2013.pdf.

[6] D. Bergström, S. Israelsson, M. Öhman, S.A. Dahlqvist, R. Gref, C. Boman, I. Wästerlund, Effects of raw material particle size distribution on the characteristics of Scots pine sawdust fuel pellets, Fuel Processing Technology. 89 (2008) 1324-1329. doi:10.1016/j.fuproc.2008.06.001.

[7] P. Lehtikangas, Quality properties of pelletised sawdust, logging residues and bark, 
Biomass and Bioenergy. 20 (2001) 351-360. doi:10.1016/S0961-9534(00)00092-1.

[8] M.T. Carone, A. Pantaleo, A. Pellerano, Influence of process parameters and biomass characteristics on the durability of pellets from the pruning residues of Olea europaea L, Biomass and Bioenergy. 35 (2011) 402-410. doi:10.1016/j.biombioe.2010.08.052.

[9] L.G. Tabil, Binding and pelleting characteristics of alfalfa pellets, $\mathrm{PhD}$ thesis, University of Saskatchewan, Canada, 1996.

[10] M. Temmerman, P.D. Jensen, J. Hébert, Von Rittinger theory adapted to wood chip and pellet milling, in a laboratory scale hammermill, Biomass and Bioenergy. 56 (2013) 70-81. doi:10.1016/j.biombioe.2013.04.020.

[11] R.J. Gravelsins, Studies of grinding of wood and bark-wood mixtures with the Szego mill, $\mathrm{PhD}$ thesis, University of Toronto, Canada, 1998.

[12] L.J. Naimi, A Study of Cellulosic Biomass Size Reduction, PhD thesis, The University of British Columbia, Canada, 2016.

[13] K. Frühmann, A. Reiterer, E.K. Tschegg, S.S. Stanzl-tschegg, Fracture characteristics of wood under mode I, mode II and mode III loading, Philosophical Magazine A. 82 (2002) 3289-3298. doi:10.1080/01418610208240441.

[14] S. Vasic, S. Stanzl-Tschegg, Experimental and numerical investigation of wood fracture mechanisms at different humidity levels, Holzforschung. 61 (2007) 367374. doi:10.1515/HF.2007.056.

[15] P.J.M. Pelgrom, M.A.I. Schutyser, R.M. Boom, Thermomechanical Morphology of 
Peas and Its Relation to Fracture Behaviour, Food and Bioprocess Technology. 6 (2013) 3317-3325. doi:10.1007/s11947-012-1031-2.

[16] T. Filbakk, G. Skjevrak, O. Høibø, J. Dibdiakova, R. Jirjis, The influence of storage and drying methods for Scots pine raw material on mechanical pellet properties and production parameters, Fuel Processing Technology. 92 (2011) 871-878. doi:10.1016/j.fuproc.2010.12.001.

[17] N.P.K. Nielsen, D. Gardner, T. Poulsen, C. Felby, Importance of temperature, moisture content, and species for the conversion process of wood residues into fuel pellets, Wood and Fiber Science. 41 (2009) 414-425.

[18] B.J. Ahn, H. sun Chang, S.M. Lee, D.H. Choi, S.T. Cho, G. seong Han, I. Yang, Effect of binders on the durability of wood pellets fabricated from Larix kaemferi C. and Liriodendron tulipifera L. sawdust, Renewable Energy. 62 (2014) 18-23. doi:10.1016/j.renene.2013.06.038.

[19] T.O. Wilson, Factors affecting wood pellet durability, Master's thesis, The Pennsylvania State University, USA, 2010.

[20] W. Stelte, J.K. Holm, A.R. Sanadi, S. Barsberg, J. Ahrenfeldt, U.B. Henriksen, A study of bonding and failure mechanisms in fuel pellets from different biomass resources, Biomass and Bioenergy. 35 (2011) 910-918. doi:10.1016/j.biombioe.2010.11.003.

[21] A.M. Olsson, L. Salmen, Viscoelasticity of insitu lignin as affected by structure softwood and hardwood, Acs Symposium Series. 489 (1992) 133-143. 
[22] J. Chirife, M. Del, P. Buera, Water Activity, Glass Transition and Microbial Stability in Concentrated / Semimoist Food Systems, 59 (n.d.) 921-927.

[23] R. Samuelsson, M. Thyrel, M. Sjöström, T.A. Lestander, Effect of biomaterial characteristics on pelletizing properties and biofuel pellet quality, Fuel Processing Technology. 90 (2009) 1129-1134. doi:10.1016/j.fuproc.2009.05.007.

[24] N. Kaliyan, R. Vance Morey, Factors affecting strength and durability of densified biomass products, Biomass and Bioenergy. 33 (2009) 337-359. doi:10.1016/j.biombioe.2008.08.005.

[25] S. Döring, Power from Pellets, 2015. doi:10.1017/CBO9781107415324.004.

[26] International Organization for Standardization, ISO 17830:2016 Solid biofuels Particle size distribution of disintegrated pellets, (2014) 1-8.

[27] A. Sluiter, B. Hames, R. Ruiz, C. Scarlata, J. Sluiter, D. Templeton, D. Crocker, Determination of structural carbohydrates and lignin in Biomass, 2012. doi:NREL/TP-510-42618.

[28] B. Hames, R. Ruiz, C. Scarlata, A. Sluiter, J. Sluiter, D. Templeton, Preparation of samples for compositional analysis laboratory analytical procedure (LAP), 2008.

[29] E. Alakangas, Properties of wood fuels used in Finland - BIOSOUTH -project, Bulk Solids Handling. (2005).

[30] I. Obernberger, G. Thek, Effects of pelletizing pressure and the addition of woody bulking agents on the physical and mechanical, Earthscan Ltd. (2010) 241-272. http://bios-bioenergy.at/uploads/media/The-Pellet-Handbook-Flyer.pdf (accessed 
August 8, 2017).

[31] J.S. Tumuluru, C.T. Wright, K.L. Kenny, J.R. Hess, A Review on Biomass Densification Technologies for Energy Application, Idaho National Laboratory. (2010).

[32] J.K. Holm, U.B. Henriksen, J.E. Hustad, L.H. Sørensen, Toward an understanding of controlling parameters in softwood and hardwood pellets production, Energy and Fuels. 20 (2006) 2686-2694. doi:10.1021/ef0503360.

[33] International Organization for Standardization, ISO 17225-2:2014 - Solid biofuels Fuel specifications and classes - Part 2: Graded wood pellets, (2014) 7-8.

[34] International Organization for Standardization, ISO 17831-1:2015 - Solid biofuels Determination of mechanical durability of pellets and briquettessh Standards, (2015).

[35] International Organization for Standardization, ISO 18134-1:2015 - Solid biofuels Determination of moisture content - Oven dry method, (2015).

[36] S.J. Blott, K. Pye, Particle shape: A review and new methods of characterization and classification, Sedimentology. 55 (2008) 31-63. doi:10.1111/j.13653091.2007.00892.x.

[37] O. Williams, G. Newbolt, C. Eastwick, S. Kingman, D. Giddings, S. Lormor, E. Lester, Influence of mill type on densified biomass comminution, Applied Energy. 182 (2016) 219-231. doi:10.1016/j.apenergy.2016.08.111.

[38] M. Masche, M. Puig-Arnavat, J. Wadenbäck, S. Clausen, P.A. Jensen, J. Ahrenfeldt, U.B. Henriksen, Wood pellet milling tests in a suspension-fired power plant, Fuel 
Processing Technology. 173 (2018) 89-102. doi:10.1016/j.fuproc.2018.01.009.

[39] Retsch Technology GmbH, Manual Evaluation Software Camsizer® X2, (2017) 188.

[40] A. Trubetskaya, G. Beckmann, J. Wadenbäck, J.K. Holm, S.P. Velaga, R. Weber, One way of representing the size and shape of biomass particles in combustion modeling, Fuel. 206 (2017) 675-683. doi:10.1016/j.fuel.2017.06.052.

[41] E.P. Cox, A Method of Assigning Numerical and Percentage Values to the Degree of Roundness of Sand Grains, Journal of Paleontology. 1 (1927) 179-183.

[42] W. Pichler, A. Weidenhiller, J. Denzler, R. Goetzl, M. Pain, M. Weigl, A. Haider, Modelling the particle size distribution of the feedstock for pellets production, 22nd European Biomass Conference and Exhibition, Hamburg, Germany. (2014) 25-26.

[43] T. Allen, Powder Sampling and Particle Size Determination, 1st ed., Elsevier Science, Oxford, UK, 2003.

[44] L.J. Naimi, S. Sokhansanj, X. Bi, C. J. Lim, A. R. Womac, A. K. Lau, S. Melin, Development of Size Reduction Equations for Calculating Energy Input for Grinding Lignocellulosic Particles, Applied Engineering in Agriculture. 29 (2013) 93-100. doi:10.13031/2013.42523.

[45] L.G. Austin, A commentary on the Kick, Bond and Rittinger laws of grinding, Powder Technology. 7 (1973) 315-317. doi:10.1016/0032-5910(73)80042-7.

[46] T. Tanaka, Comminution Laws. Several Probabilities, Industrial \& Engineering Chemistry Process Design and Development. 5 (1966) 353-358. 
doi:10.1021/i260020a001.

[47] R.H. White, Effect of lignin content and extractives on the higher heating value of wood, Wood and Fiber Science. 19 (1987) 446-452. http://swst.metapress.com/index/1NJ2H77X84TJ8057.pdf.

[48] Acetyl-Methoxyl Content of Softwoods \& Hardwoods, The University of Tennessee. (2018). http://biorefinery.utk.edu/technical_reviews/methoxyl acetyl content wood.pdf (accessed July 5, 2018).

[49] H. Hartmann, T. Böhm, P. Daugbjerg Jensen, M. Temmerman, F. Rabier, M. Golser, Methods for size classification of wood chips, Biomass and Bioenergy. 30 (2006) 944-953. doi:10.1016/j.biombioe.2006.06.010.

[50] D.N. Lanning, J.H. Dooley, C.J. Lanning, Shear Processing of Wood Chips into Feedstock Particles, 2012 ASABE Annual International Meeting. 1 (2012) 703-714.

[51] A. Twaddle, The influence of species, chip length, and ring orientation on chip thickness, Tappi Journal. 80 (1997) 121-131.

[52] L.S. Esteban, J.E. Carrasco, Evaluation of different strategies for pulverization of forest biomasses, 166 (2006) 139-151. doi:10.1016/j.powtec.2006.05.018.

[53] O. Oyedeji, O. Fasina, S. Adhikari, T. McDonald, S. Taylor, The effect of storage time and moisture content on grindability of loblolly pine (Pinus taeda L.), European Journal of Wood and Wood Products. 74 (2016) 857-866. doi:10.1007/s00107-0161070-x.

[54] R. Marton, N. Tsujimoto, E. Eskelinen, Energy consumption in thermomechanical 
pulping, Tappi Journal. 64 (1981) 71-74.

[55] Z. Lu, X. Hu, Y. Lu, Particle Morphology Analysis of Biomass Material Based on Improved Image Processing Method, International Journal of Analytical Chemistry. 2017 (2017) 1-9. doi:10.1155/2017/5840690.

[56] P. Daugbjerg Jensen, M. Temmerman, S. Westborg, Internal particle size distribution of biofuel pellets, Fuel. 90 (2011) 980-986. doi:10.1016/j.fuel.2010.11.029.

[57] W. Stelte, A.R. Sanadi, L. Shang, J.K. Holm, J. Ahrenfeldt, U.B. Henriksen, Recent developments in biomass pelletization - a review, 7 (2012) 4451-4490.

[58] M.R. Wu, D.L. Schott, G. Lodewijks, Physical properties of solid biomass, Biomass and Bioenergy. 35 (2011) 2093-2105. doi:10.1016/j.biombioe.2011.02.020.

[59] C. Kirsten, V. Lenz, H. Schröder, J. Repke, Hay pellets — The influence of particle size reduction on their physical - mechanical quality and energy demand during production, Fuel Processing Technology. 148 (2016) 163-174. doi:10.1016/j.fuproc.2016.02.013.

[60] P. Lehtikangas, Storage effects on pelletised sawdust, logging residues and bark, Biomass and Bioenergy. 19 (2000) 287-293. doi:10.1016/S0961-9534(00)00046-5.

[61] N.P.K. Nielsen, D.J. Gardner, C. Felby, Effect of extractives and storage on the pelletizing process of sawdust, Fuel. 89 (2010) 94-98. doi:10.1016/j.fuel.2009.06.025.

[62] H. Rezaei, C.J. Lim, A. Lau, S. Sokhansanj, Size, shape and flow characterization of ground wood chip and ground wood pellet particles, Powder Technology. 301 (2016) 
737-746. doi:10.1016/j.powtec.2016.07.016.

[63] M. Grabner, U. Müller, N. Gierlinger, R. Wimmer, Effects of heartwood extractives on mechanical properties of larch, IAWA Journal. 26 (2005) 211-220.

[64] M.P.C. Conrad, G.D. Smith, G. Fernlund, Fracture of solid wood: A review of structure and properties at different length scales, Wood and Fiber Science. 35 (2003) 570-584.

[65] E.N. Landis, P. Navi, Modeling crack propagation in wood and wood composites. A review. COST Action E35 2004-2008: Wood machining - Micromechanics and fracture, Holzforschung. 63 (2009) 150-156. doi:10.1515/HF.2009.010.

[66] O. Williams, E. Lester, S. Kingman, D. Giddings, S. Lormor, C. Eastwick, Benefits of dry comminution of biomass pellets in a knife mill, Biosystems Engineering. 160 (2017) 42-54. doi:10.1016/j.biosystemseng.2017.05.011.

[67] M. Akgul, A. Tozluoglu, Some Chemical and Morphological Properties of Juvenile Woods from Beech (Fagus orientalis L.) and Pine (Pinus nigra A.) Plantations, Trends in Applied Sciences Research. 4 (2009) 116-125. doi:10.3923/tasr.2009.116.125.

[68] K. Tannous, P.S. Lam, S. Sokhansanj, J.R. Grace, Physical properties for flow characterization of ground biomass from douglas fir wood, Particulate Science and Technology. 31 (2013) 291-300. doi:10.1080/02726351.2012.732676.

[69] Q. Guo, X. Chen, H. Liu, Experimental research on shape and size distribution of biomass particle, Fuel. 94 (2012) 551-555. doi:10.1016/j.fuel.2011.11.041. 
[70] A. Trubetskaya, Y. Poyraz, R. Weber, J. Wadenbäck, Secondary comminution of wood pellets in power plant and laboratory-scale mills, Fuel Processing Technology. 160 (2017) 216-227. doi:10.1016/j.fuproc.2017.02.023.

[71] N. Chevanan, A. R. Womac, V. S. Bitra, S. Sokhansanj, Effect of Particle Size Distribution on Loose-filled and Tapped Densities of Selected Biomass after Knife Mill Size Reduction, Applied Engineering in Agriculture. 27 (2011) 631-644. doi:10.13031/2013.38194.

[72] A. Bodhmage, Correlation between physical properties and flowability indicators for fine powders, Master's thesis, University of Saskatchewan, Canada, 2006. http://www.collectionscanada.gc.ca/obj/s4/f2/dsk3/SSU/TC-SSU07032006115722.pdf.

[73] Sketch ring die pellet, TU Munich. (2009). https://mediatum.ub.tum.de/image/732175 (accessed June 18, 2018). 


\section{Figure captions}

Fig. 1: Major processing steps of converting whole trees to pellets for pulverized wood-fired power plant boilers.

Fig. 2: Limbed and debarked beech (left) and pine (right) logwood.

Fig. 3: Experimental mill setup and the three milling steps performed at the pellet plant.

Fig. 4: Perforated ring die (left). Operating principle of the ring die pellet mill (right) adapted from [73].

Fig. 5: Illustration of the length, width, and thickness of a typical wood chip.

Fig. 6: Average cumulative undersize mass distribution of as-received beech and pine wood chips obtained by sieve analysis. Error bars indicate the first standard deviation from the mean, and they are displayed when greater than the data symbol.

Fig. 7: Average dimensions of beech chips (hollow symbols) and pine chips (solid symbols) in each sieve fraction compared to the mean sieve mesh size. Error bars indicate the 95\% confidence internal, and they are displayed when greater than the data symbol.

Fig. 8: Average cumulative undersize volume PSD versus $d_{c, \text { min }}(A)$ and average cumulative undersize volume PSD versus $\mathrm{d}_{\mathrm{Fe}, \max }(\mathrm{B})$ analyzed by Camsizer ${ }^{\circledR} \mathrm{X}$ 2.

Fig. 9: Average circularity (A) and elongation ratio (B) of fine grinds, disintegrated pellets, and milled pellets for beech and pine analyzed by Camsizer® X2. Values for particles wider than $1 \mathrm{~mm}$ were neglected due to the small number of particles analyzed. 
Fig. 10: Specific grinding energy consumption vs. Von Rittinger's size reduction ratio (A) and specific grinding energy consumption vs. characteristic product particle size (B). 


\section{Table captions}

Table 1: Chemical composition of pine and beech wood (\% dry matter).

Table 2: Milling performance of pine and beech in a series of hammer mills. Size parameters are analyzed by sieve analysis and presented as means with three replicates.

Table 3: Quality parameters of the pellet specimens and performance of $6 \mathrm{~mm}$-sized pine and beech pellets produced in a ring pellet die. Size parameters are presented as means with three replicates.

Table 4: Physical properties of fine grinds, disintegrated pellets, and milled pellets. Values are presented as means with three replicates, and one standard deviation is indicated in parentheses.

Table 5: Estimation of the process energies for milling and pelletizing prior to the combustion of wood pellets based on the net calorific value of the oven dry matter $\left(N C V_{d}\right)$. 


\section{Tables and Figures}

Fig. 1:

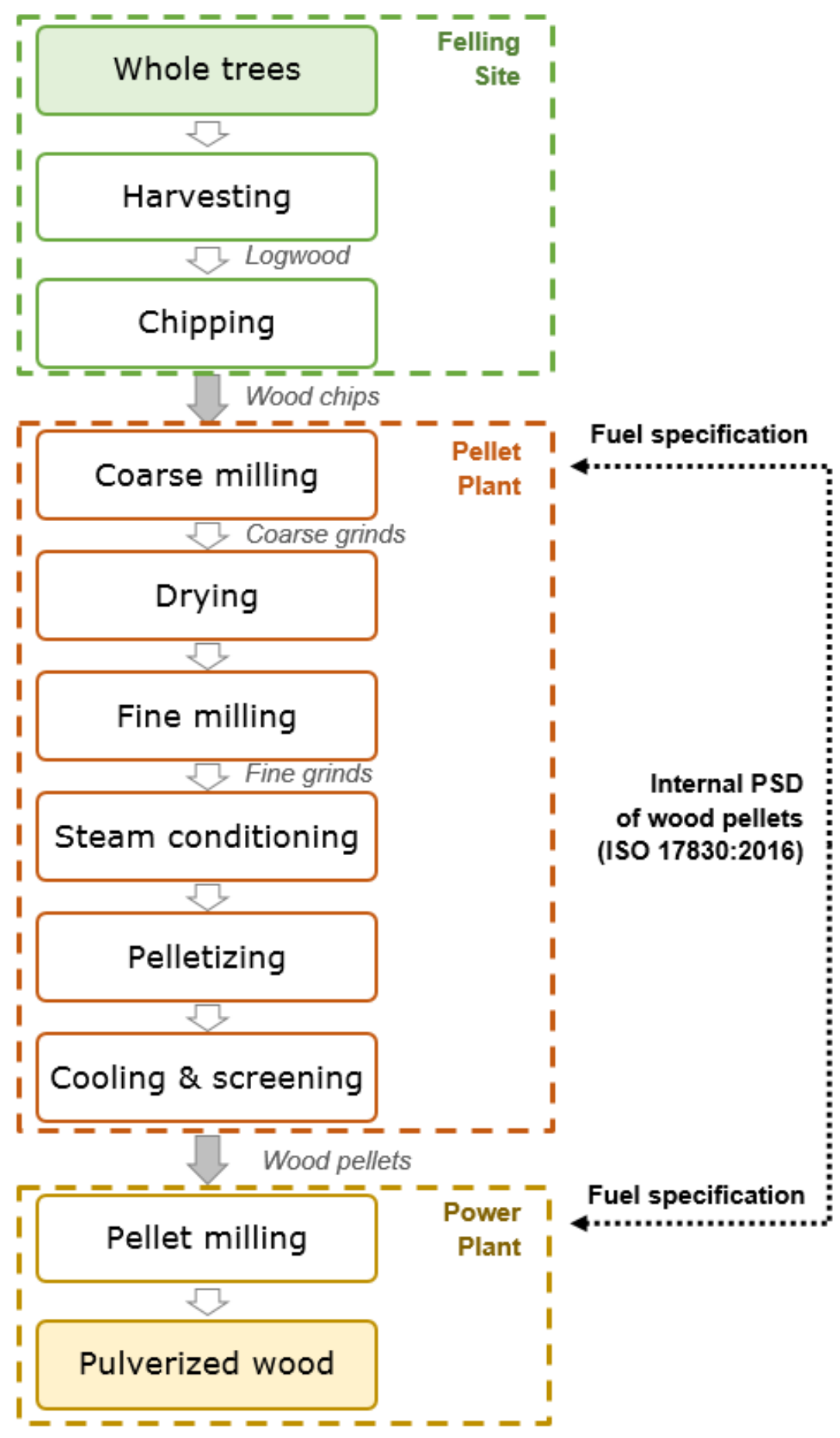




\section{Fig. 2:}

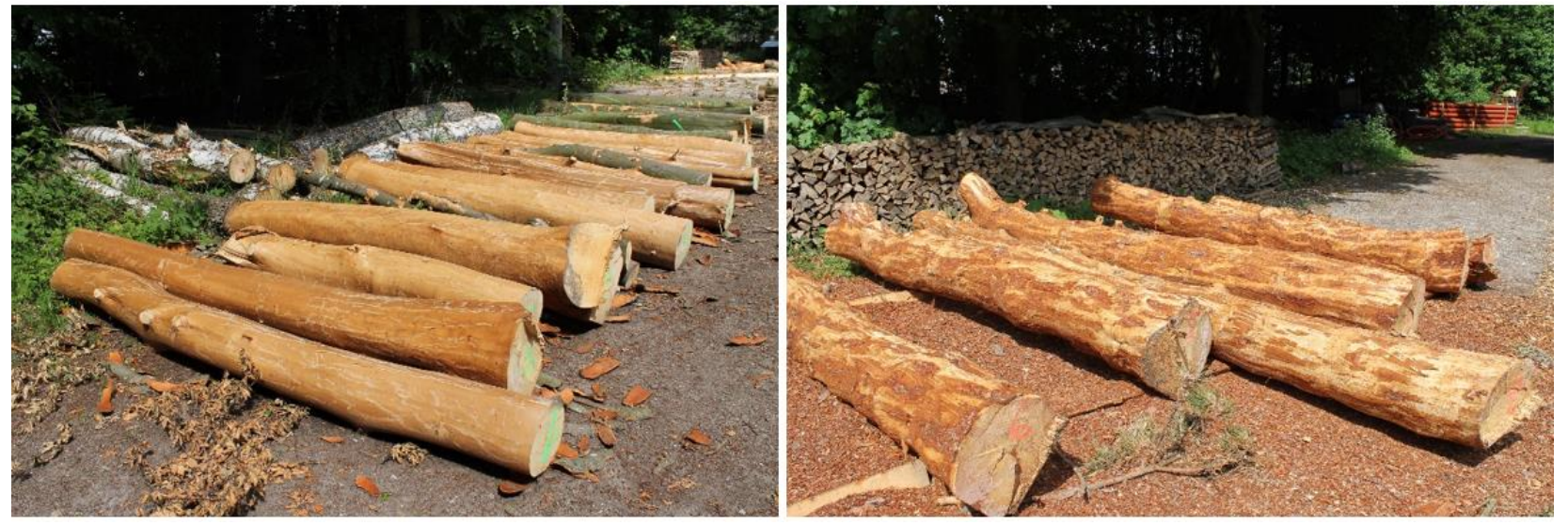




\section{Fig. 3:}

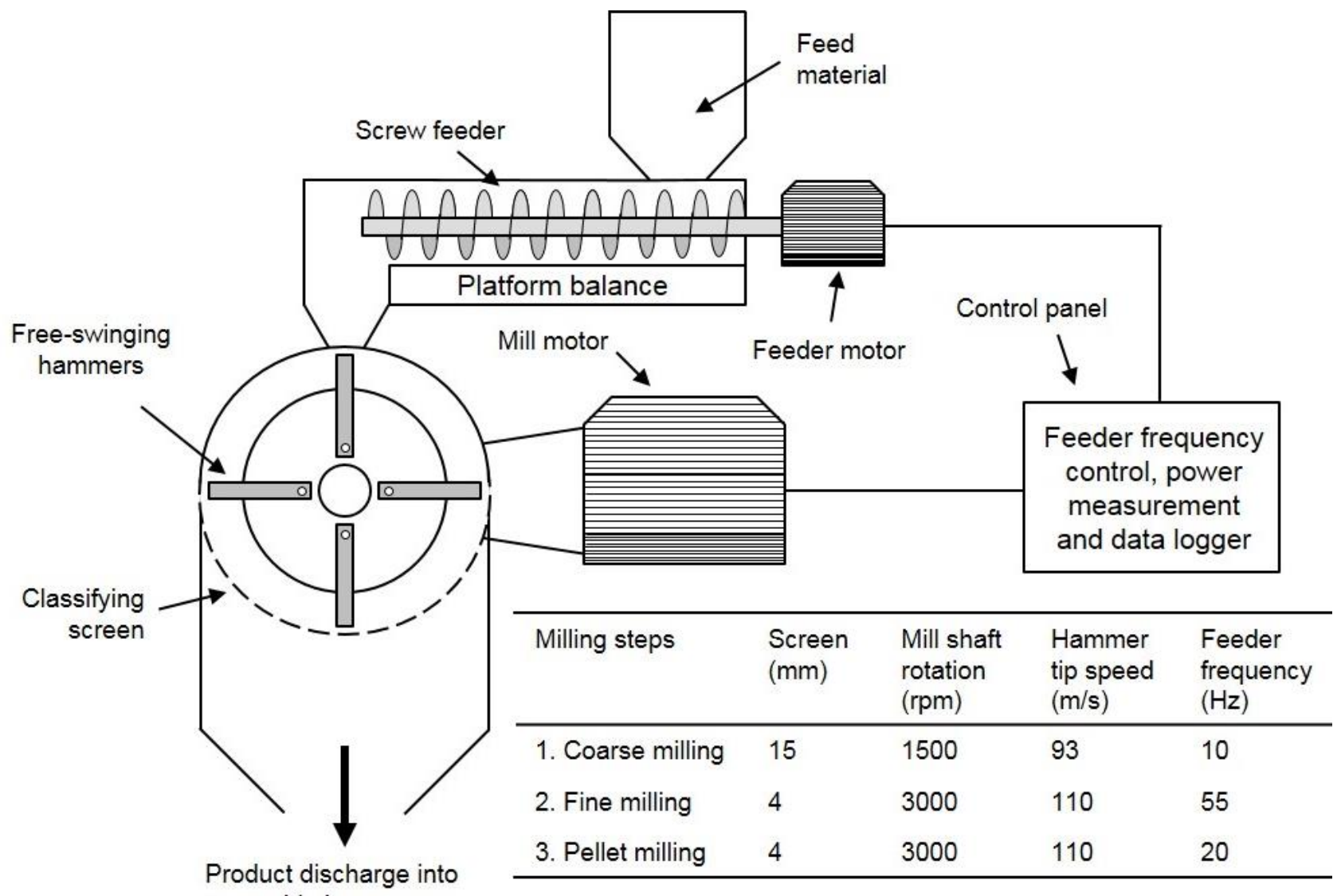

big bags 


\section{Fig. 4:}
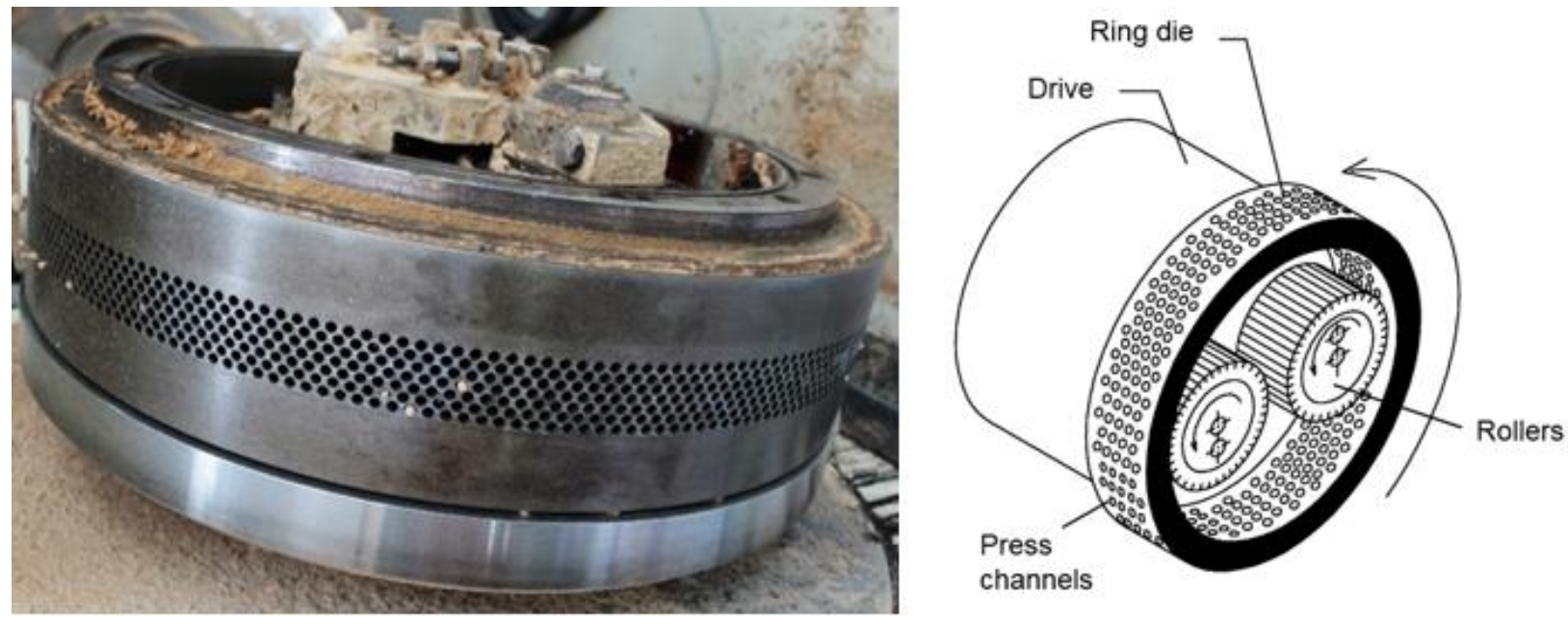


\section{Fig. 5:}

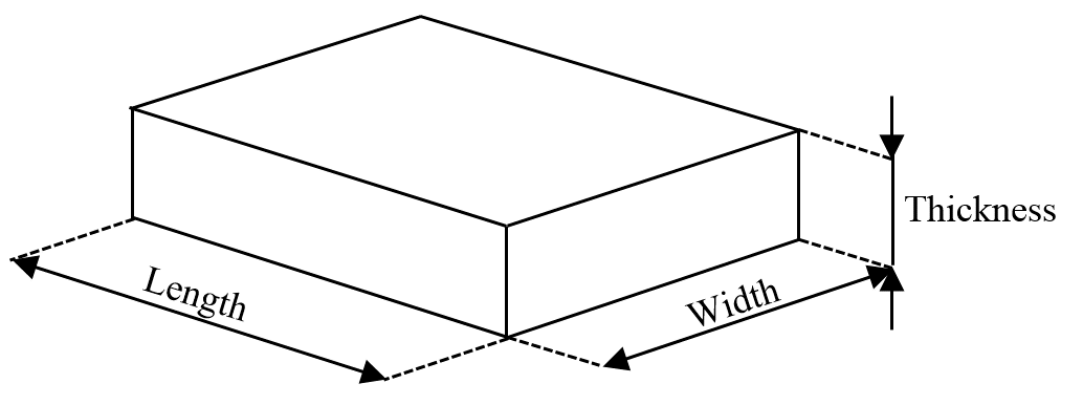




\section{Fig. 6:}

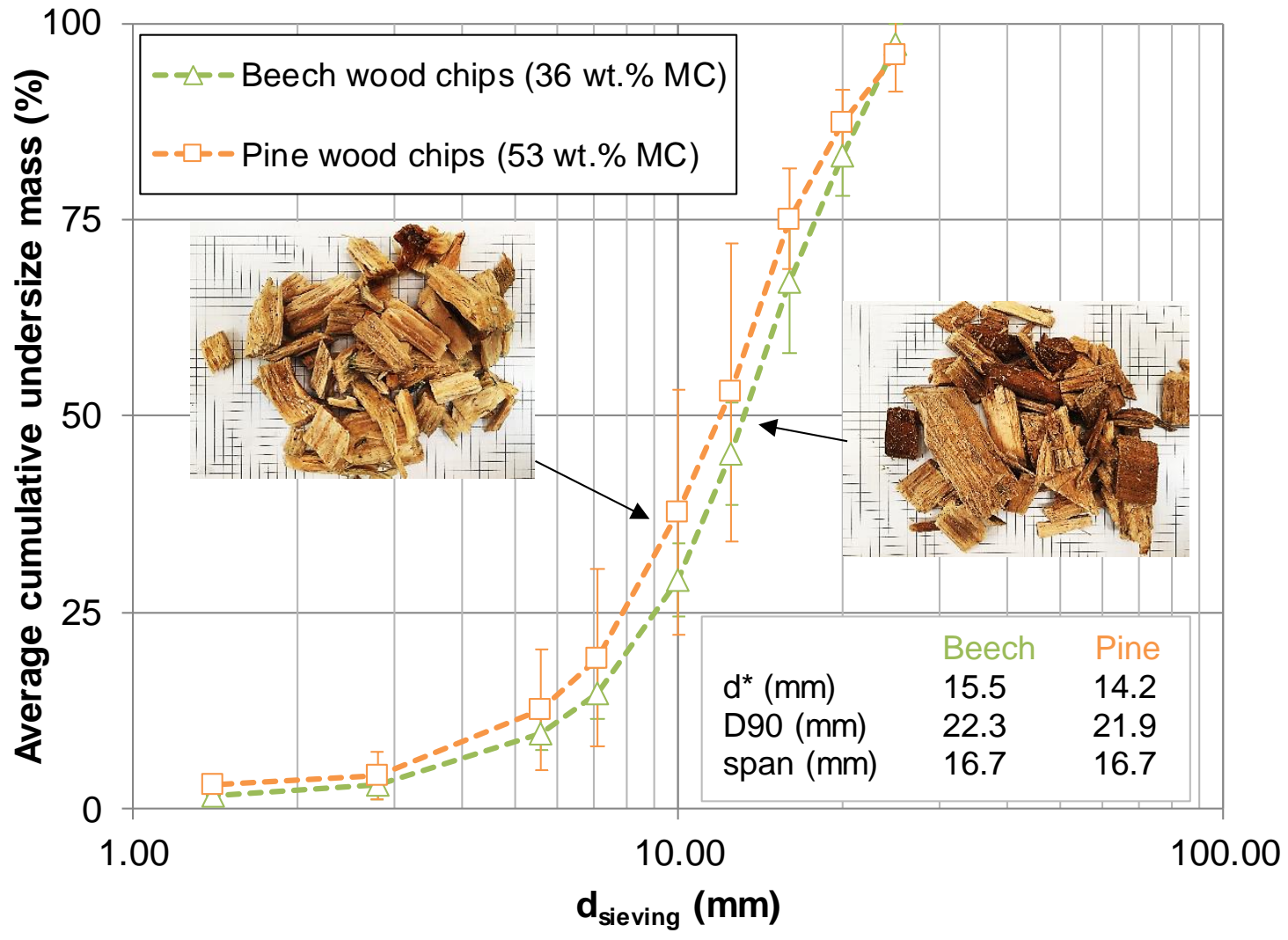




\section{Fig. 7:}

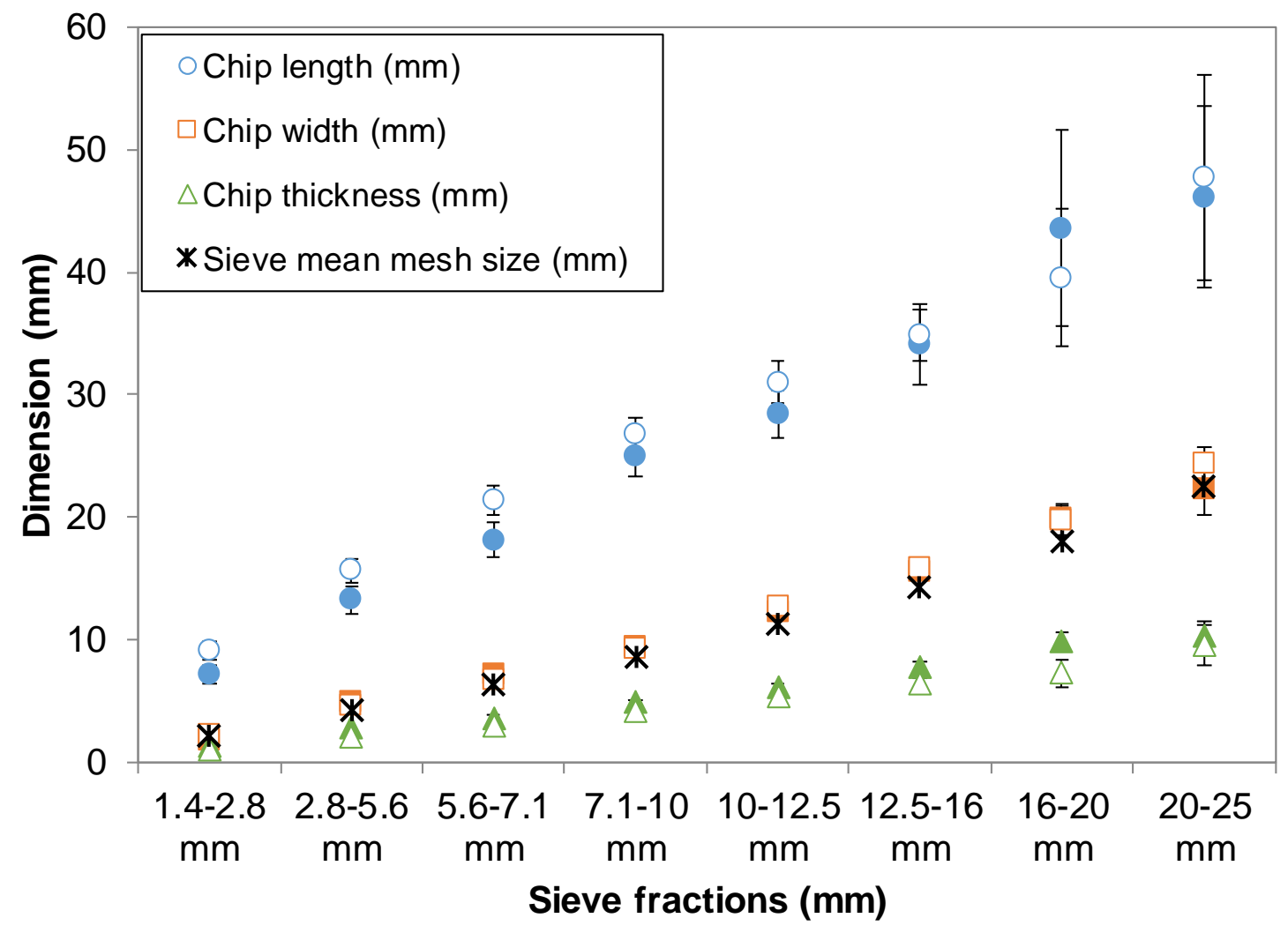




\section{Fig. 8:}
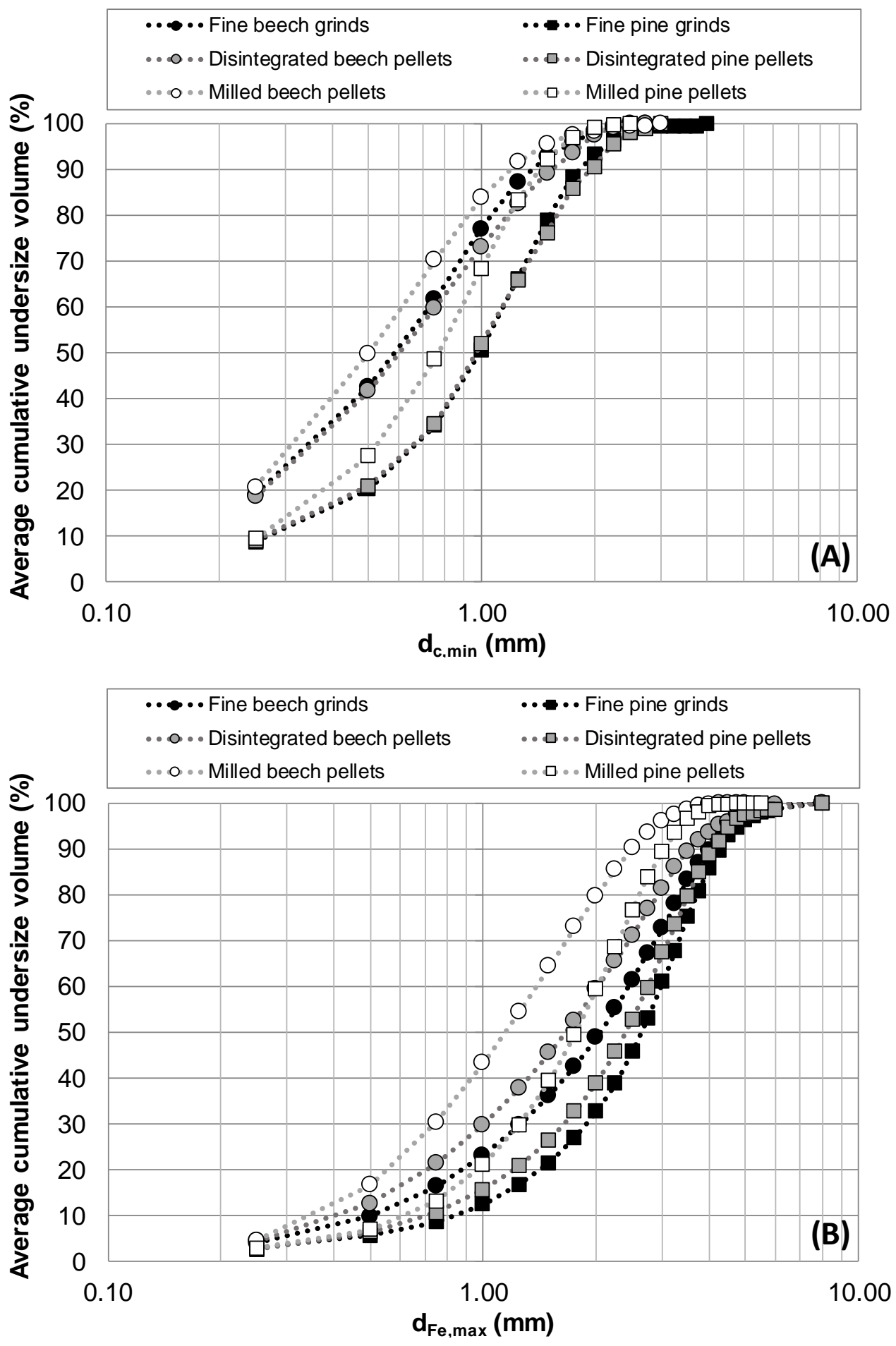

Masche et al. / Mechanical processing pathway of wood / 48 


\section{Fig. 9:}
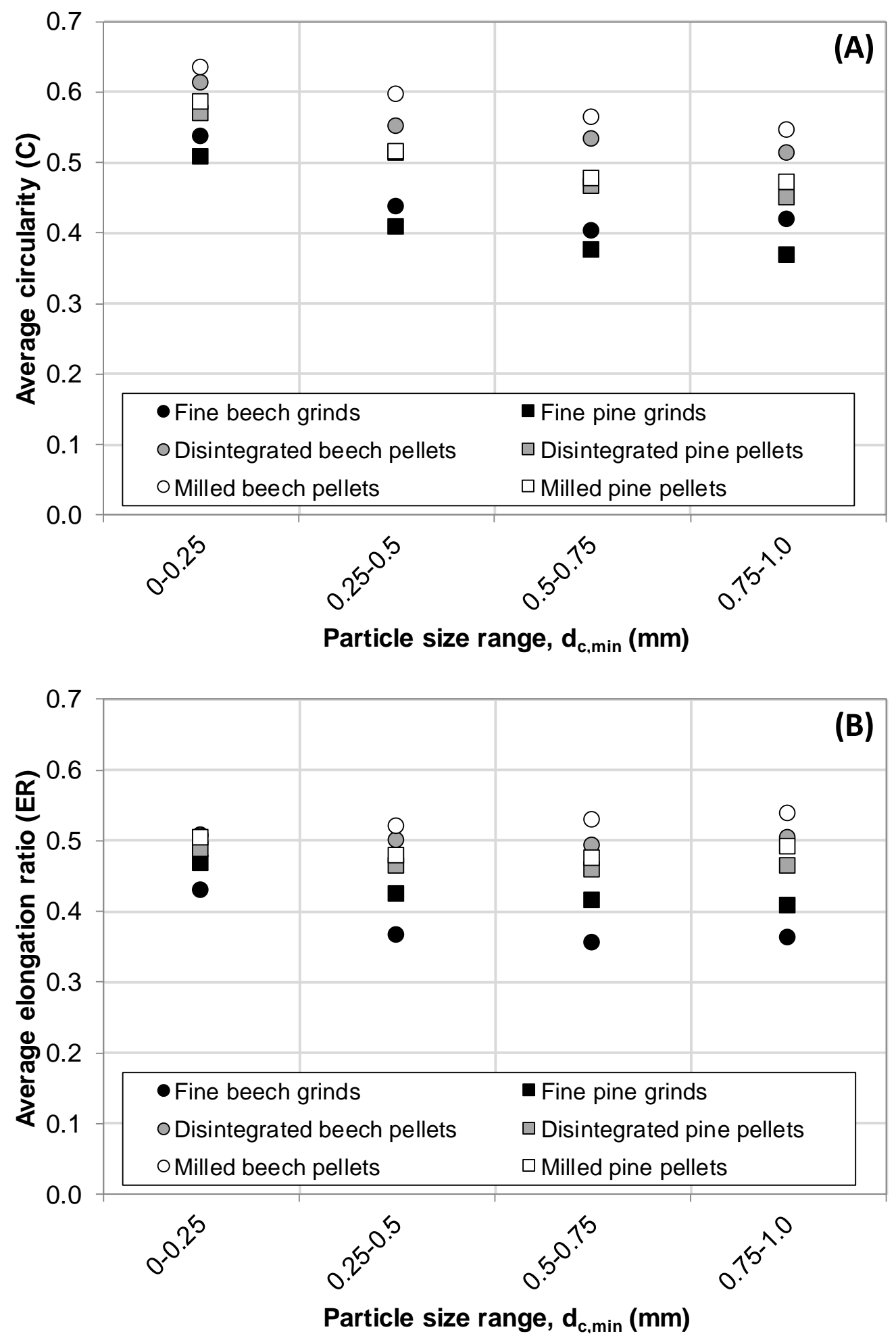
Fig. 10:
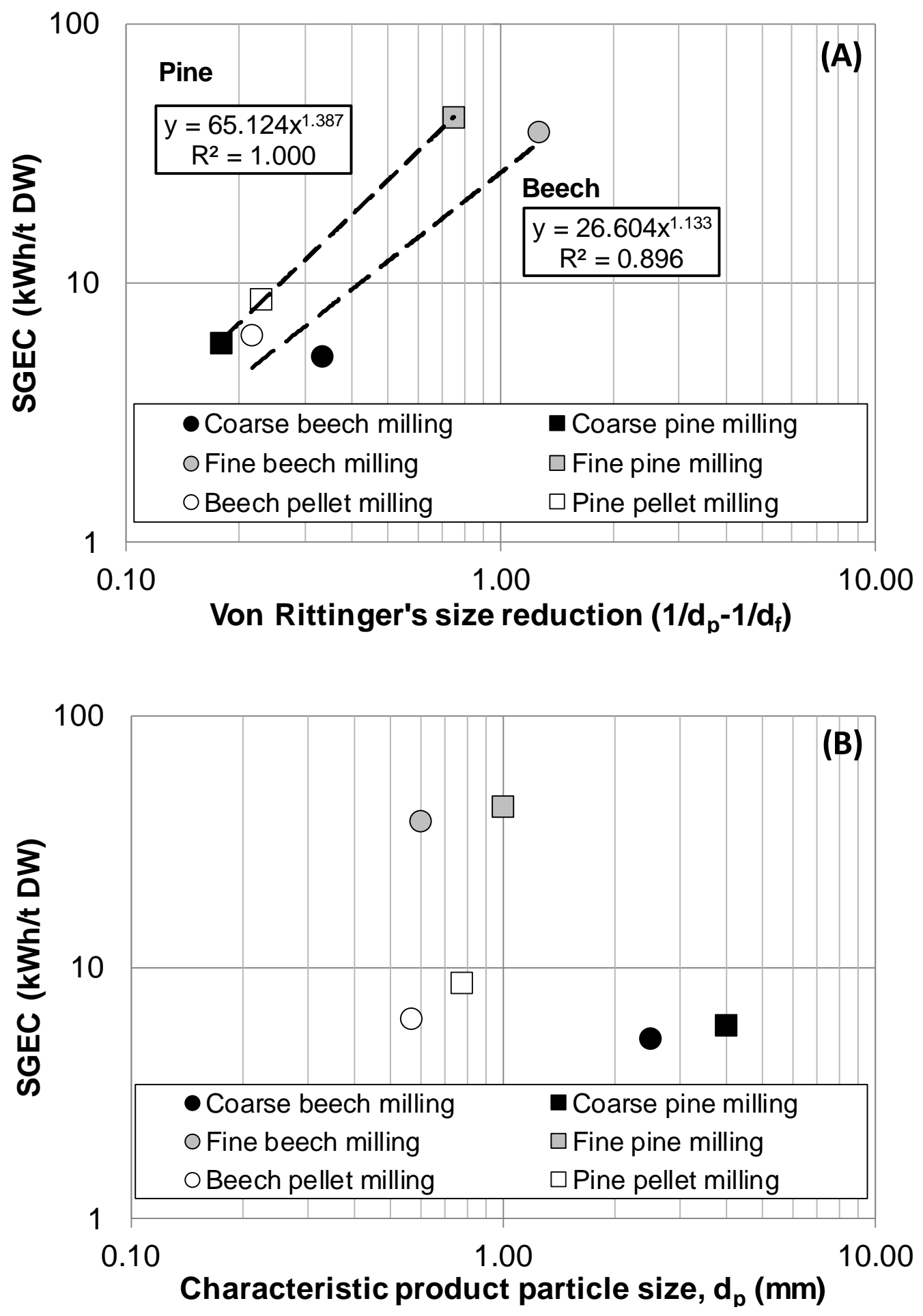
Table 1:

\begin{tabular}{|c|c|c|c|c|c|c|c|c|c|c|c|}
\hline \multirow[t]{2}{*}{ Wood } & \multicolumn{5}{|c|}{ Carbohydrates } & \multirow{2}{*}{$\begin{array}{l}\text { Klason } \\
\text { lignin }\end{array}$} & \multirow{2}{*}{$\begin{array}{l}\text { Acid } \\
\text { soluble } \\
\text { lignin }\end{array}$} & \multicolumn{2}{|c|}{ Extractives } & \multirow[t]{2}{*}{ Ash } & \multirow[t]{2}{*}{ Total } \\
\hline & Total & Glucan & Xylan & Mannan & Others $^{1}$ & & & $\begin{array}{l}\text { Water- } \\
\text { soluble }\end{array}$ & $\begin{array}{l}\text { Ethanol- } \\
\text { soluble }\end{array}$ & & \\
\hline Beech & 63.8 & 39.2 & 18.0 & 1.7 & 4.9 & 23.4 & 2.9 & 0.9 & 0.9 & 0.5 & 92.4 \\
\hline Pine & 59.4 & 38.1 & 4.3 & 11.3 & 5.8 & 24.8 & 0.6 & 4.5 & 10.6 & 0.6 & 100.6 \\
\hline
\end{tabular}

${ }^{1}$ Sum of arabinan, galactan, rhamnan, and uronics. 
Table 2:

\begin{tabular}{llllllll}
\hline Feed material & Screen & $\mathrm{d}_{\mathrm{f}}{ }^{1}$ & $\mathrm{~d}_{\mathrm{p}}{ }^{2}$ & $\mathrm{SRR}^{3}$ & Capacity & $\mathrm{K}_{\mathrm{R}}{ }^{4}$ & Total SGEC $^{5}$ \\
& $(\mathrm{~mm})$ & $(\mathrm{mm})$ & $(\mathrm{mm})$ & $\left(1 / \mathrm{d}_{\mathrm{p}}-1 / \mathrm{d}_{\mathrm{f}}\right)$ & $(\mathrm{t} \mathrm{DW} / \mathrm{h})$ & $\left(\mathrm{kWh} \mathrm{mm} \mathrm{t}{ }^{-1} \mathrm{DW}\right)$ & $(\mathrm{kWh} / \mathrm{t} \mathrm{DW})$
\end{tabular}

\section{Coarse milling}

Beech chips

15

$\begin{array}{lll}15.46 & 2.45 \quad 0.34\end{array}$

0.54

27.0

8.1

(36 wt.\% $\mathrm{MC}^{6}$ )

Pine chips 15

$\begin{array}{lll}14.18 & 3.97 \quad 0.18\end{array}$

0.36

62.8

12.6

(53 wt.\% MC)

\section{Fine milling}

Coarse beech grinds 4

$\begin{array}{llll}2.45 & 0.60 & 1.26 & 0.98\end{array}$

33.5

43.6

(12 wt.\% MC)

Coarse pine grinds

4

$\begin{array}{lll}3.97 & 0.97 & 0.78\end{array}$

0.90

61.8

49.4

(12 wt.\% MC)

\section{Pellet milling}

Beech pellets

$\begin{array}{lll}0.65^{7} & 0.57 & 0.23\end{array}$

2.87

30.5

6.6

(4.2 wt.\% MC)

Pine pellets

$\begin{array}{llll}4 & 0.95^{7} & 0.78 & 0.22\end{array}$

2.75

41.4

9.5

(8.5 wt.\% MC)

${ }^{1} \mathrm{~d}_{\mathrm{f}}$ : characteristic particle size of the feed.

${ }^{2} d_{\mathrm{p}}$ : characteristic particle size of the product.

${ }^{3}$ SRR: Von Rittinger's size reduction ratio.

${ }^{4} \mathrm{~K}_{\mathrm{R}}$ : Von Rittinger's material characteristic parameter.

${ }^{5}$ SGEC: specific grinding energy consumption.

${ }^{6} \mathrm{MC}:$ moisture content.

${ }^{7} \mathrm{~d}_{\mathrm{f}}$ : characteristic particle size of the disintegrated pellet material. 
Table 3:

\begin{tabular}{|c|c|c|c|c|}
\hline & Unit & Beech & Pine & Analysis method \\
\hline \multicolumn{5}{|l|}{ Pellet feed properties } \\
\hline Feed moisture & wt.\% & 8.4 & 8.8 & ISO 18134-1: 2015 \\
\hline Feed d* & $\mathrm{mm}$ & 0.6 & 1.0 & Sieve analysis \\
\hline Feed span & $\mathrm{mm}$ & 1.0 & 1.4 & Sieve analysis \\
\hline Feed bulk density & $\mathrm{kg} / \mathrm{m}^{3}$ & 215.1 & 177.6 & ISO 17828: 2015 \\
\hline \multicolumn{5}{|l|}{ Pellet quality parameters } \\
\hline Pellet moisture & wt. $\%$, ar & 4.2 & 8.5 & ISO 18134-1: 2015 \\
\hline Pellet diameter (D) & $\mathrm{mm}$, ar & $\mathrm{D}, 6.1$ & $\mathrm{D}, 6.1$ & ISO 17829: 2015 \\
\hline and length (L) & & $\mathrm{L}, 11.8$ & $\mathrm{~L}, 10.1$ & \\
\hline Number of pellets/ & & 366 & 350 & Counting of pellets screened \\
\hline $100 \mathrm{~g}$ sample of pellets & & & & using a $5.0 \mathrm{~mm}$ sieve \\
\hline Net calorific value & $\mathrm{MJ} / \mathrm{kg}, \mathrm{DW}$ & 18.4 & 19.8 & ISO 18125:2017 \\
\hline Bulk density $\left(\sigma_{\mathrm{B}}\right)$ & $\mathrm{kg} / \mathrm{m}^{3}$, ar & 580.4 & 603.3 & ISO 17828: 2015 \\
\hline $\begin{array}{l}\text { Specific pellet } \\
\text { density }\left(\sigma_{\mathrm{P}}\right)\end{array}$ & $\mathrm{kg} / \mathrm{m}^{3}$, ar & 1113.8 & 1152.6 & $\sigma_{P}=\frac{m}{V_{p}}$ \\
\hline Interparticle porosity $(\varepsilon)$ & - & 0.48 & 0.48 & $\varepsilon=1-\frac{\sigma_{P}}{\sigma_{B}}$ \\
\hline Mechanical durability & wt. $\%$, ar & 96.7 & 98.5 & ISO 17831-1: 2015 \\
\hline \multirow{6}{*}{$\begin{array}{l}\text { PSD of disintegrated } \\
\text { pellets (internal PSD) }\end{array}$} & wt.\%, DW & $\geq 100 \%{ }^{1}$ & $\geq 100.0 \%$ & ISO 17830: 2016 \\
\hline & & $(<3.15 \mathrm{~mm})$ & $(<3.15 \mathrm{~mm})$ & (Sieve analysis) \\
\hline & & $\geq 99.3 \%{ }^{1}$ & $\geq 97.7 \%$ & \\
\hline & & $(<2.0 \mathrm{~mm})$ & $(<2.0 \mathrm{~mm})$ & \\
\hline & & $\geq 84.3 \%^{1}$ & $\geq 62.7 \%$ & \\
\hline & & $(<1.0 \mathrm{~mm})$ & $(<1.0 \mathrm{~mm})$ & \\
\hline \multicolumn{5}{|l|}{ Pelletizing performance } \\
\hline Die channel length & $\mathrm{mm}$ & 35 & 50 & \\
\hline Capacity & $\mathrm{t} \mathrm{DW/h}$ & 0.68 & 0.69 & \\
\hline Total SEC & $\mathrm{kWh} / \mathrm{t} \mathrm{DW}$ & 90.3 & 35.0 & \\
\hline
\end{tabular}

${ }^{1}$ Values obtained after the second pellet disintegration in hot water. 
Table 4:

\begin{tabular}{|c|c|c|c|c|c|c|c|c|}
\hline \multirow[t]{3}{*}{ Wood samples } & \multicolumn{6}{|c|}{ Size and shape parameter analyzed by DIA } & \multirow{3}{*}{$\begin{array}{l}\text { Moisture } \\
\text { content } \\
\text { (wt.\%) }\end{array}$} & \multirow{3}{*}{$\begin{array}{l}\text { Loose bulk } \\
\text { density } \\
\left(\mathrm{kg} / \mathrm{m}^{3}\right)\end{array}$} \\
\hline & $d^{* 1}$ & $\operatorname{span}^{1}$ & $d^{* 2}$ & $\operatorname{span}^{2}$ & ER & $\mathrm{C}$ & & \\
\hline & $(\mathrm{mm})$ & $(\mathrm{mm})$ & $(\mathrm{mm})$ & $(\mathrm{mm})$ & $(-)$ & $(-)$ & & \\
\hline \multirow[t]{2}{*}{ Fine beech grinds } & 0.77 & 1.25 & 2.32 & 3.54 & 0.38 & 0.45 & 8.4 & 215.1 \\
\hline & $(0.05)$ & $(0.04)$ & $(0.10)$ & $(0.07)$ & $(0.01)$ & $(0.02)$ & $(0.1)$ & $(9.2)$ \\
\hline \multirow[t]{2}{*}{ Disintegrated ${ }^{3}$ beech pellets } & 0.79 & 1.41 & 1.81 & 2.88 & 0.51 & 0.55 & 6.2 & 210.5 \\
\hline & $(0.12)$ & $(0.14)$ & $(0.13)$ & $(0.19)$ & $(0.04)$ & $(0.03)$ & $(0.1)$ & $(8.7)$ \\
\hline \multirow[t]{2}{*}{ Milled beech pellets } & 0.68 & 1.08 & 1.47 & 2.13 & 0.52 & 0.57 & 3.5 & 396.1 \\
\hline & $(0.03)$ & $(0.04)$ & $(0.05)$ & $(0.05)$ & $(0.01)$ & $(0.01)$ & $(0.1)$ & (7.3) \\
\hline \multirow[t]{2}{*}{ Fine pine grinds } & 1.17 & 1.61 & 2.85 & 3.43 & 0.41 & 0.41 & 8.8 & 177.6 \\
\hline & $(0.02)$ & $(0.02)$ & $(0.03)$ & $(0.06)$ & $(0.01)$ & $(0.03)$ & $(0.1)$ & $(8.2)$ \\
\hline \multirow[t]{2}{*}{ Disintegrated pine pellets } & 1.16 & 1.65 & 2.64 & 3.10 & 0.48 & 0.50 & 6.4 & 170.8 \\
\hline & $(0.09)$ & $(0.03)$ & $(0.07)$ & $(0.08)$ & $(0.03)$ & $(0.03)$ & $(0.1)$ & $(8.5)$ \\
\hline \multirow[t]{2}{*}{ Milled pine pellets } & 0.90 & 1.18 & 1.94 & 2.42 & 0.49 & 0.51 & 7.4 & 282.8 \\
\hline & $(0.04)$ & $(0.04)$ & $(0.03)$ & $(0.05)$ & $(0.02)$ & $(0.01)$ & $(0.1)$ & $(6.2)$ \\
\hline
\end{tabular}

${ }^{1}$ Size characteristics calculated based on $\mathrm{d}_{\mathrm{c}, \min }$.

${ }^{2}$ Size characteristics calculated based on $\mathrm{d}_{\mathrm{Fe} \text {,max }}$.

${ }^{3}$ Material obtained after the second pellet disintegration in hot water. 
Table 5:

\begin{tabular}{|c|c|c|c|c|c|c|}
\hline \multirow[b]{2}{*}{ Wood } & \multirow[b]{2}{*}{$\begin{array}{l}\mathrm{NCV}_{\mathrm{d}} \\
(\mathrm{MJ} / \mathrm{kg}, \mathrm{DW})\end{array}$} & \multicolumn{3}{|l|}{ Pellet plant } & \multirow{2}{*}{$\begin{array}{l}\text { Power plant } \\
\mathrm{SEC}_{\text {pellet milling }} \\
\mathrm{NCV}_{\mathrm{d}}(\%)\end{array}$} & \multirow{2}{*}{$\begin{array}{l}\text { Total } \\
(\%)\end{array}$} \\
\hline & & $\begin{array}{l}\mathrm{SEC}_{\text {coarse milling }} / \\
\mathrm{NCV}_{\mathrm{d}}(\%)\end{array}$ & $\begin{array}{l}\mathrm{SEC}_{\text {fine milling }} / \\
\mathrm{NCV}_{\mathrm{d}}(\%)\end{array}$ & $\begin{array}{l}\mathrm{SEC}_{\text {pelletizing }} / \mathrm{NCV}_{\mathrm{d}} \\
(\%)\end{array}$ & & \\
\hline Beech & 18.4 & 0.16 & 0.85 & 1.77 & 0.13 & 2.91 \\
\hline Pine & 19.8 & 0.23 & 0.90 & 0.64 & 0.17 & 1.94 \\
\hline
\end{tabular}




\section{Supplementary material}

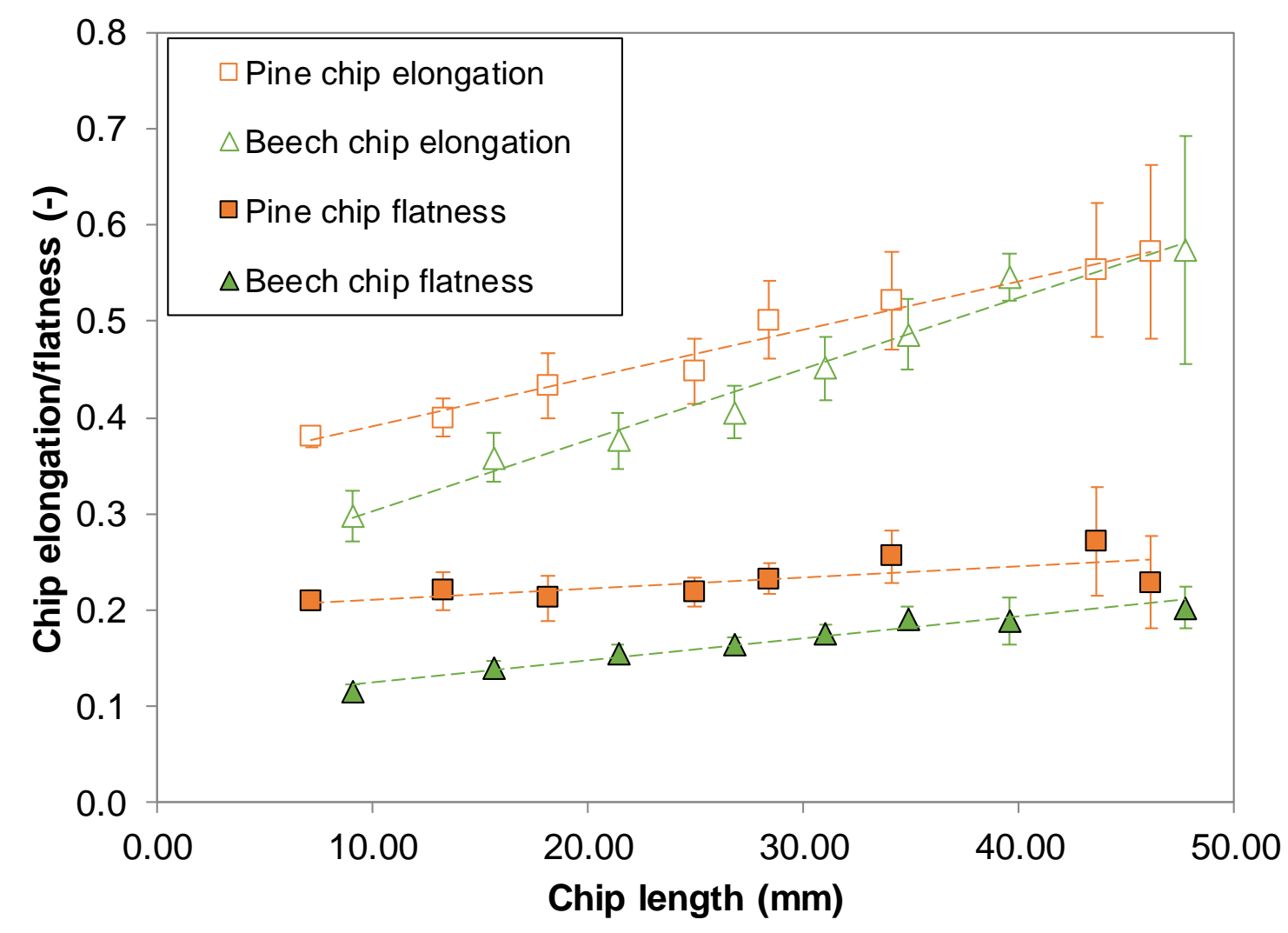

Fig. S1: Average shape factors of beech and pine wood chips as a function of the chip length. Error bars indicate the $95 \%$ confidence internal, and they are displayed when greater than the data symbol. 


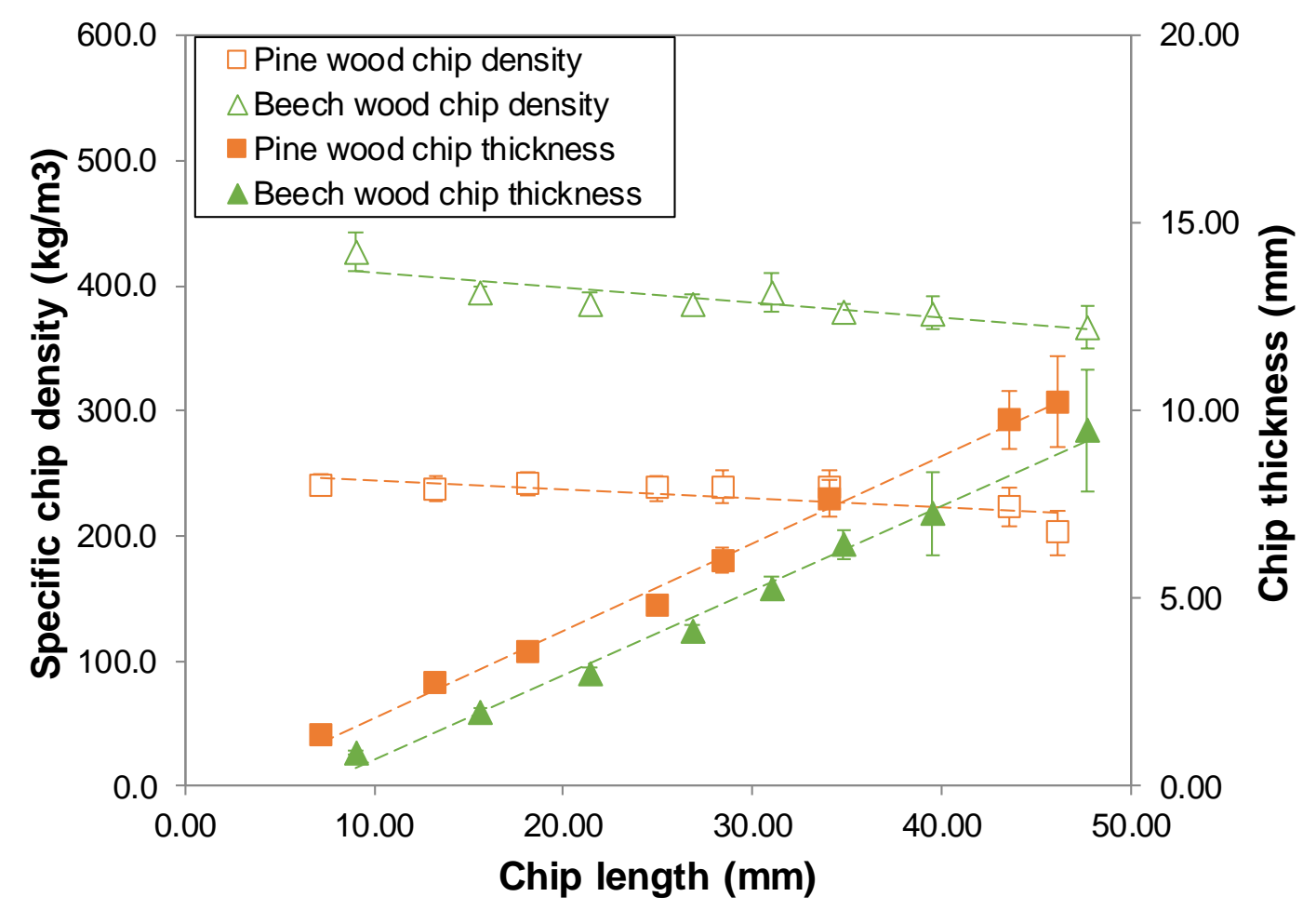

Fig. S2: Average specific density and thickness of beech and pine wood chips as a function of the chip length. Error bars indicate the $95 \%$ confidence internal, and they are displayed when greater than the data symbol. 


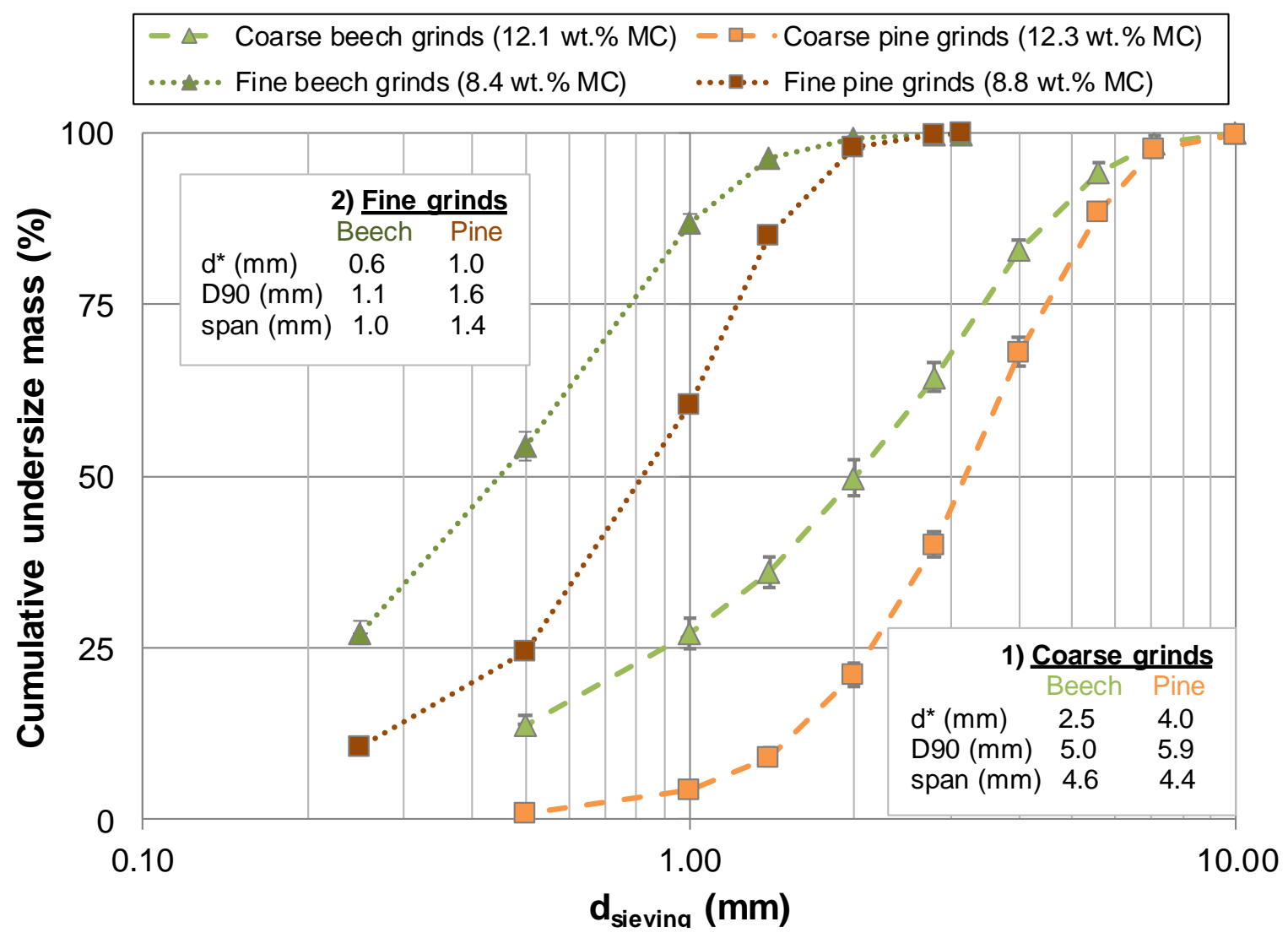

Fig. S3: Average cumulative undersize mass distribution of coarse and fine grinds of beech and pine obtained by sieve analysis. Error bars indicate the first standard deviation from the mean, and they are displayed when greater than the data symbol. 


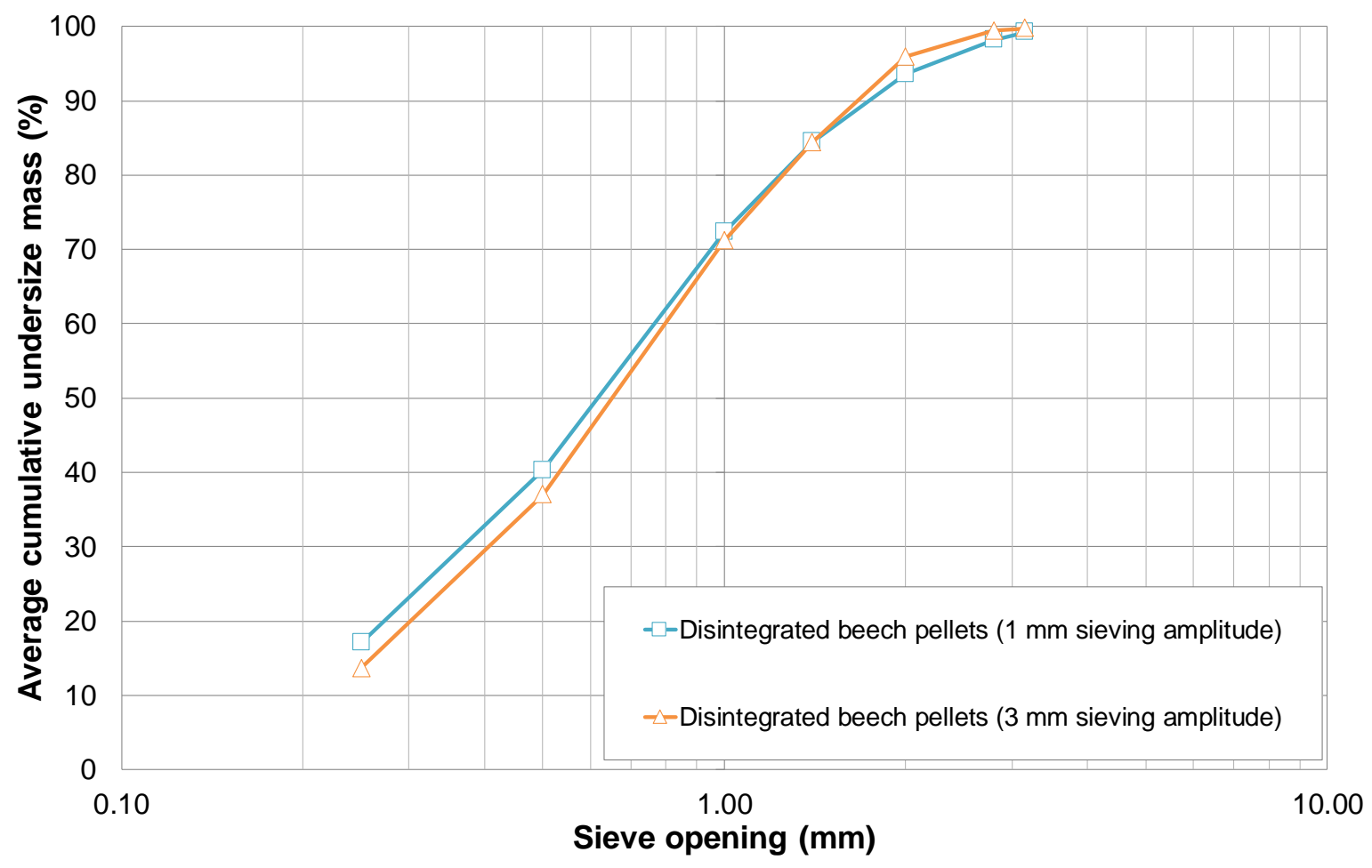

Fig. S4: Influence of sieving amplitude on the particle size distribution of disintegrated beech pellets. Average sieving data are presented. 

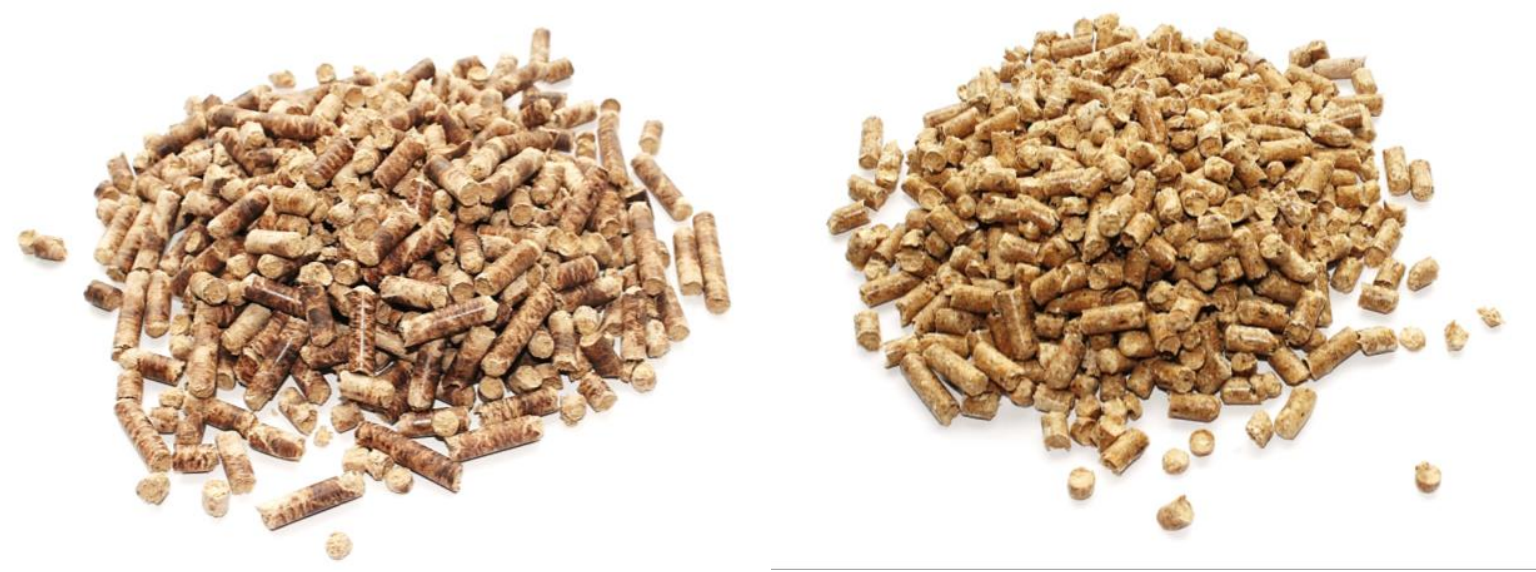

Fig. S5: Appearance of beech pellets (left) and pine pellets (right). 